\title{
Probabilistic Seismic Hazard Assessment for Jamaica
}

\author{
Walter Salazar ${ }^{1}$, Lyndon Brown ${ }^{2}$ and Garth Mannette ${ }^{1}$ \\ 1. Seismic Research Centre, The University of the West Indies (UWI), St. Augustine, Trinidad and Tobago \\ 2. Earthquake Unit, The University of the West Indies (UWI), Mona, Kingston, Jamaica
}

\begin{abstract}
A probabilistic seismic hazard analysis was performed to generate seismic hazard maps for Jamaica. The analysis was then conducted using a standard logic-tree approach that allowed systematically taking into account the model-based (i.e., epistemic) uncertainty and its influence on the computed ground motion parameters. Hazard computations have been performed using a grid of sites with a space of 0.05 degrees. Two different computation methodologies have been adopted: the standard approach based on the definition of appropriate seismogenic sources and the zone-free approach, which overcomes the ambiguities related with the definition of the seismic sources solely reflecting the characteristics of the earthquake catalogue. A comprehensive and updated earthquake catalogue for Jamaica has been compiled for the years 1551-2010 and new empirical relationships amongst magnitudes $M_{W}-M_{S}$ and $M_{W}-m_{b}$ have been developed for the region. Uniform hazard spectra and their uncertainty have been calculated for the horizontal component of ground motion for rock site conditions and five return periods $(95,475,975,2,475$ and 4,975 years) and spectral accelerations for 34 structural periods ranging from 0 to $3 \mathrm{~s}$, and $5 \%$ of critical damping. The spectral accelerations have been calculated to allow the definition of seismic hazard in Jamaica according to the International Building Code 2012. The disaggregation analysis for Kingston Metropolitan Area suggests that the magnitude-distance pair that contributes most to the hazard corresponds to events with M 7.8 and M 7.0 in the Enriquillo Plantain Garden Fault and the Jamaican Faults at a distance of $28 \mathrm{~km}$ and $18 \mathrm{~km}$ for short and long period structures respectively corresponding to 2,475 years return period. However, for long period structures, a substantial contribution is found for a M 8.2 at a distance of $198 \mathrm{~km}$ in the Oriente Fault Zone.
\end{abstract}

Key words: Earthquake catalogue, GMPE's (ground motion prediction equations), seismic hazard, response spectrum, disaggregation analysis.

\section{Introduction}

Pereira and Gay [1] and Shepherd and Aspinall [2] were the first to prepare probabilistic seismic hazard maps for Jamaica in terms of MMI (Modified Mercalli Intensity). However, it was not until the 1990s that much more effort was put into the determination of seismic hazard in the Caribbean in terms of PGA (peak ground acceleration): McQueen [3] undertook an evaluation of seismic hazard in the Caribbean and Central America using three techniques: (1) the classical source-zone or Cornell-McGuire method [4, 5]; (2) extreme value method [6, 7]; and (3) historic parametric method [8]. The former two constitutes free-zone methods for which no geological and

\footnotetext{
Corresponding author: Walter Salazar, doctor of engineering, research fellow, research fields: earthquake engineering and engineering seismology. E-mail: walter.salazar@uwiseismic.com.
}

tectonic information are used to define the seismogenic sources to determine the hazard. The historic parametric method was found to be more stable under varying conditions of computation and thereafter became the most common method used for seismic hazard assessments in the Caribbean, as a result Tanner and Shepherd [9] and Shedlock [10] produced the first systematic and detailed regional seismic hazard map using the historic parametric method setting a 475 year return period. More recently, García et al. [11] proposed seismic hazard maps for Cuba and surrounding areas including Jamaica for PGA setting also 475 year return period employing the classical Cornell McGuire approach.

The first section of this work is devoted to explain the construction of a new earthquake catalogue and to the tectonic environment and the seismicity evaluation for Jamaica and surrounding areas. Secondly, the 
authors present the GMPE's (ground motion prediction equations) adopted to compute the hazard, those compatible with the tectonics of the region. Thirdly, the authors compute a new set of probabilistic seismic hazard maps for Jamaica and surrounding areas for both the PGA and absolute spectral acceleration for periods of $0.2 \mathrm{~s}$ and $1.0 \mathrm{~s}$ which are compatible with the International Building Code [12] based on new seismological and tectonic information that has arisen in the last decade. Additionally, the associated uncertainty in the maps produced by the combination of zone [4, 5] and zone-free methods [13] has been explained in this research in the logic tree scheme, a UHS (uniform hazard spectrum) is presented for KMA (Kingston metropolitan area) as well. Finally, the magnitude-distance pairs that contribute most to the hazard are presented with the aim of having compatible time-history accelerations for the design or revision of building structures in Kingston metropolitan area.

\section{Construction of the Earthquake Catalogue}

A fundamental step of a seismic hazard assessment is the compilation of an earthquake catalogue, which has to be homogenous and contains all the possible available information from local and regional data bases accounting for both, historical and instrumental seismicity data.

In this work, a new earthquake catalogue has been compiled using the following data bases covering the geographical region $71.8^{\circ}-82.5^{\circ} \mathrm{W}$ and $15.0^{\circ}-23.0^{\circ} \mathrm{N}$ incorporating earthquakes inland Jamaica and within a distance of $400 \mathrm{~km}$ offshore of the island coastlines: (1) Bakun et al. [14]; (b) ISC (International Seismological Centre); (3) US Geological Survey Earthquake Database USGS/NEIC (NOAA); (4) US Geological Survey Earthquake Database USGS/NEIC (NGDC); (5) US Geological Survey Earthquake Database USGS/NEIC (SISRA); (6) US Geological Survey Earthquake Database USGS/NEIC (Centennial); (7) Catálogo del Instituto Panamericano de la Geografía e Historia (IPGH); (8) Earthquake Unit Local Catalogue
(UWI Mona, Jamaica); (9) Tomblin and Robson [15].

All the events selected from the sources listed above have been first placed in chronological order and then merged. Each event of the merged catalogue has been examined to determine whether or not it represented a repetition of another event, namely, listing the same time of origin of the earthquake and similar epicentral location. A hierarchy amongst the different data bases was followed respecting the order cited above and then selecting one solution per event.

Different scales of magnitude were listed in the composite catalogue, as follows:

(1) Moment magnitude $\left(M_{W}\right)$;

(2) Surface-wave magnitude $\left(M_{S}\right)$;

(3) Body-wave magnitude $\left(m_{b}\right)$;

(4) Duration magnitude $\left(M_{D}\right)$;

(5) Local or Richter magnitude $\left(M_{L}\right)$.

In order to homogenize the catalogue to a single Moment magnitude $M_{W}$, new empirical relations between $M_{W}$ and $m_{b}$ and $M_{W}$ and $M_{S}$ have been developed employing an orthogonal regression with 45 and 64 pair of magnitudes values, respectively (Fig. 1 and Table 1). In both cases, a quadratic empirical formula fits the data. For the cases of events with magnitude $M_{L}$ and $M_{D}$, relations from another part of the world have been adopted due to the scarce amount of data (Table 1).

The final catalogue contains 322 events with magnitude $M_{w}$ between 4.5-7.9 for the years 1551-2010. A minimum magnitude of 4.5 was selected to compile the catalogue since events with a lower magnitude would not cause significant damage to structures (Fig. 2). From the 322 events, 319 are shallow earthquakes with depth less than $50 \mathrm{~km}$, and only three of them have depth greater than $50 \mathrm{~km}$.

\section{Tectonic Setting and Delimitation of Seismogenic Sources}

Once the catalogue has been compiled, the authors established a geometrical delimitation for the seismogenic sources in the region and associated the 

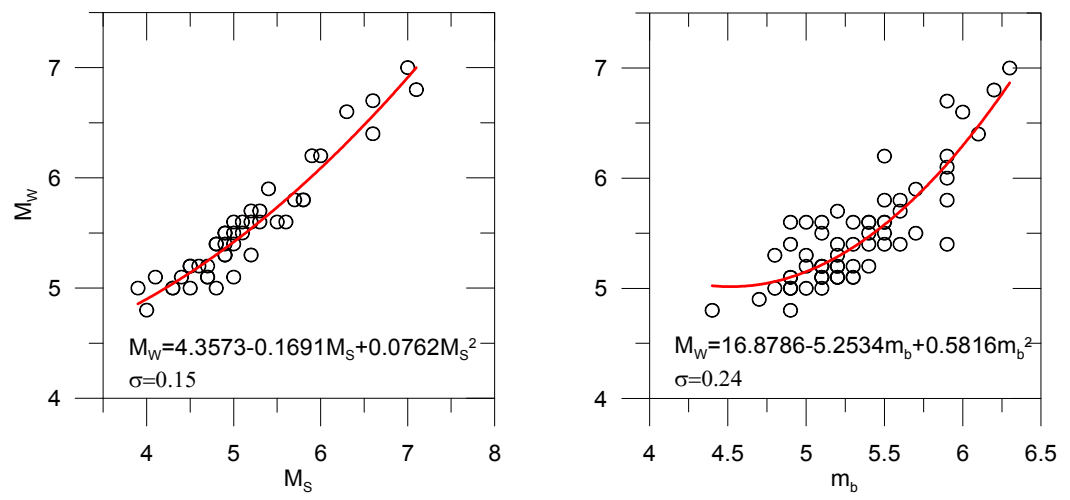

Fig. 1 Empirical relations between magnitudes $M_{W}-M_{S}$ and $M_{W}-m_{b}$.

Table 1 Empirical magnitude relations between Moment magnitude $\left(M_{w}\right)$ and Surface waves $\left(M_{S}\right)$, Body waves $\left(m_{b}\right)$, Duration $\left(M_{D}\right)$ and Local $\left(M_{L}\right)$ Magnitudes and seismic moment $\left(M_{o}\right)$.

\begin{tabular}{ll}
\hline Relation & Reference \\
\hline$M_{W}=4.3573-0.1691 M_{S}+0.0762 M_{S}^{2} \sigma=0.15$ & This work \\
$M_{W}=16.8786-5.2534 m_{b}+0.5816 m_{b}^{2} \sigma=0.24$ & This work \\
$\log M_{o}=1.51 * M_{D}+16.1$ & Pasyanos et al. [16] \\
$\log M_{\mathrm{o}}=17.53+0.63 M_{L}+0.10 M_{L}^{2}$ & Hanks and Boore [17] \\
$M_{W}=2 / 3 \log M_{o}-10.7$ & Hanks and Kanamori [18] \\
\hline
\end{tabular}

$M_{o}$ : Seismic moment in dyne-cm and $\sigma$ denotes the standard deviation obtained in the orthogonal regression in this work.

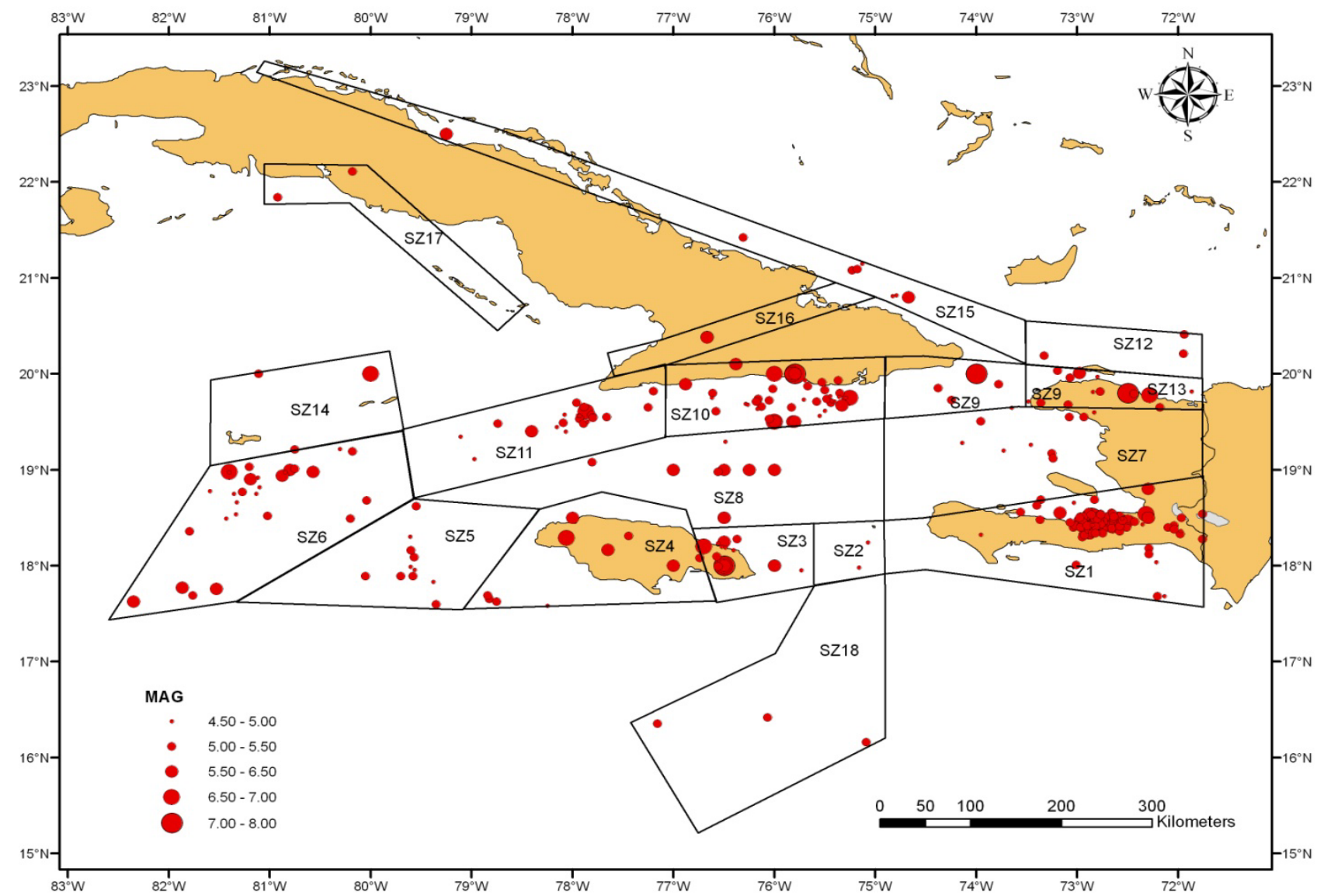

Fig. 2 Earthquake epicentres of the depurated catalogue (including foreshocks and aftershocks) and geometrical delimitation of seismogenic zones (SZ1-SZ 18) for Jamaica and surrounding areas. 
earthquakes in the catalogue to each of them. Eighteen seismogenic sources have been established from this research that affect the study area based on tectonics and geological features that have been already studied by different authors (Fig. 2). Jamaica is located on the north-central Caribbean on the Gonave microplate with a rate of $13 \mathrm{~mm} / \mathrm{yr}$ of plate motion bounded by the Oriente Fracture Zone to the North, the Cayman Spreading Center to the west, the Enriquillo Plantain Garden and the Walton Fault zones to the south. The following sources are detected in Jamaica and surrounding areas (Fig. 3).

\subsection{Zone 1-3: Enriquillo-Plantain Garden Zone and Morant Trough}

This earthquake source extends from east Jamaica from the Blue Mountain-Wagwater zone to the west of Hispaniola parallel to Oriente Fault Zone to the south resulting mainly in left-lateral motion. Classifying the main fault into two seismogenic sources (Zone 1 and 3, as shown in Fig. 2) based on the highest activity in the fault, results in the two extremes with a very low seismicity level at the center comprising the Morant Trough (Zone 2) which is an extensional submarine feature representing a pull-apart basin along the Enriquillo-Plantain Garden fault system [19] with an estimated rate of $6 \mathrm{~mm} / \mathrm{yr}$ of fault slip. Recently in Zone 1, the January 12, 2010 with a Mw 7.0 is thought to have occurred on a steeply dipping fault located just north of the main trace of the Enriquillo-Plantain Garden Fault named the Léogâne Fault [20, 21], aftershock data for this earthquake also suggest inverse motion in the west part of epicenter main shock (Fig. 2). Historical destructive earthquakes in this Fault Zone dated on 1701 in the city of Léogâne at the West of Port-au-Prince with a M 6.6, October 18, 1751 (M

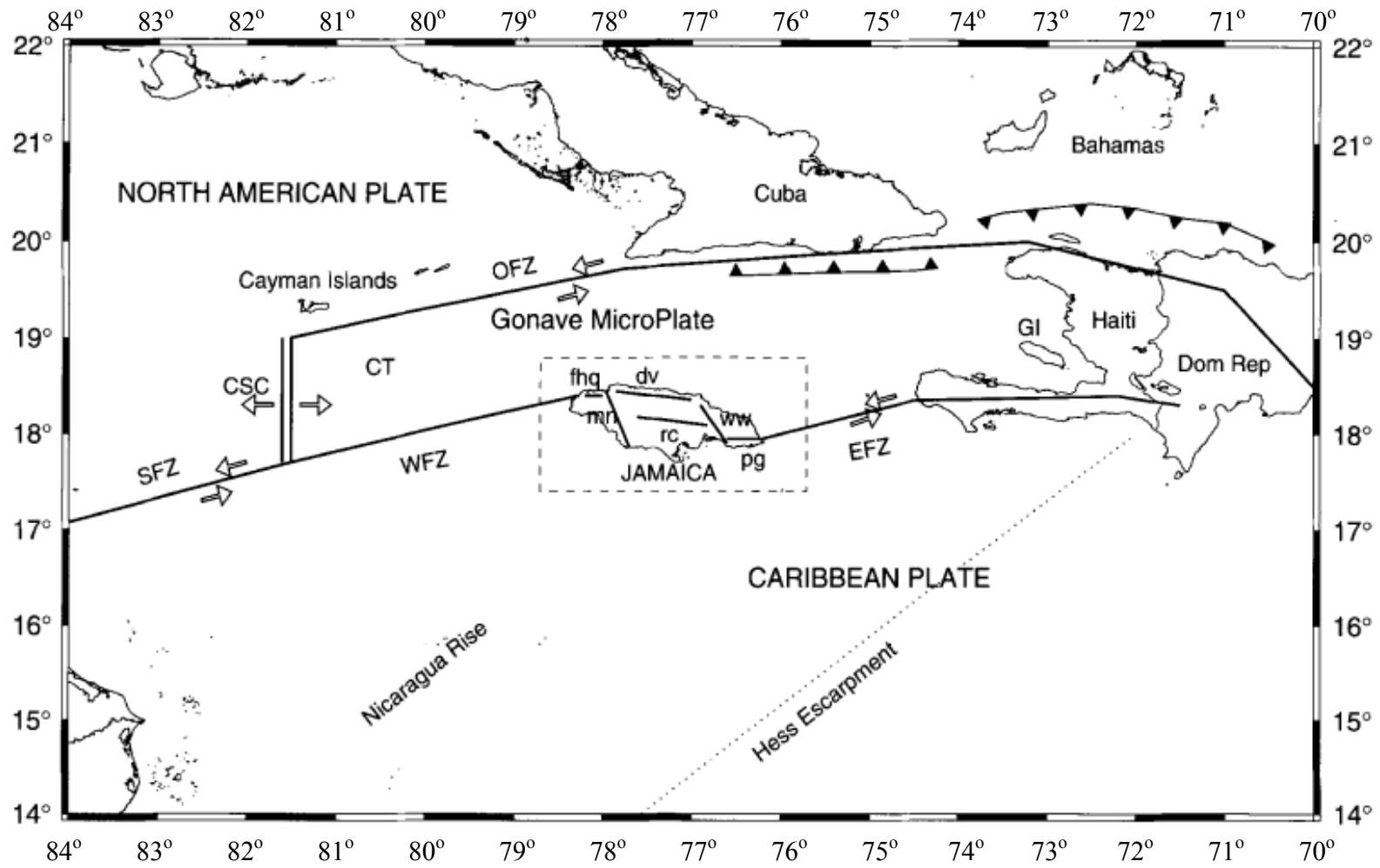

Fig. 3 Jamaica region tectonics: SFZ—Swan fracture zone; CSC-Cayman Spreading Center; CT-Cayman Trench; OFZ-Oriente fracture zone; WWF-Walton fault zone; EFZ—Enriquillo fault zone; Dom Rep-Dominican republic; GI-Gonave Island; fhq-Fat hog quarters fault; dv-Duanvale fault; ww-Wagwater fault; pg-Plantain garden fault; mn-Montepelier-Newmarket fault zone; rc-Rio Minho-Crawle river fault, reproduced with the permission of Seismological Society of America and Wiggins-Grandison [22]. 
7.5) — which it is outside of the geographical window of this study, November 21, 1751 (M 6.6), June 3, 1770 (M 7.5), April 8, 1860 (M 6.3), as shown in Ref. [14]. Frankel et al. [23] propose a slip rate of $7 \mathrm{~mm} / \mathrm{yr}$ with a maximum magnitude of 7.7 in the Plantain Garden Fault. In Zone 3, destructive earthquakes occurred in Jamaica in 1692 at Port Royal with an estimate magnitude of about 7.4 and in 1907 at Kingston with M 6.9 [24].

\subsection{Zone 4: Jamaican Faults}

The major fault trends in Jamaica are oriented in E-W and NNW-SSE direction. For the E-W direction the main faults with strike slip left lateral mechanism are the NJF (North Jamaican fault), the MF (Maryland fault), the SCF (South coastal fault) zone, the RMCR (Rio Minho-Crawle river) and the DF (Duanvale fault). In the NNW-SSE direction the faults are the MNB (Montpelier-New-Market belt) with strike slip and reverse faulting, the SC (Santa Cruz) and the ST (spur three) fault located in western Jamaica, the Wagwater (W) with reverse mechanism dipping $57^{\circ}$ and 200-500 $\mathrm{m}$ wide and Yallahs $(\mathrm{Y})$ fault located at the eastern section of the island. However, in the RMCR though thrust faulting was dominant on nearly vertical planes with east-west orientation. The maximum earthquake listed in the catalogue in this zone date on March 2, 1957 at $M w 6.6$ showing a left-lateral strike slip motion on an east-west trending fault plane, Frankel et al. [21] and Burke et al. [25] calculated an integrated slip rate of $4 \mathrm{~mm} / \mathrm{yr}$ for faults in Jamaica based on geologically mapped fault offsets and assumed offset ages, DeMets and Wiggins-Grandinson [26] calculated a motion of 7 $\mathrm{mm} / \mathrm{yr}$ for strike slip faults and $3 \mathrm{~mm} / \mathrm{yr}$ for normal faults and more recently Benford et al. [27] estimate 4-5 mm/yr in northern Jamaica for the Plantain Garden and Blue Mountain restraining bend of southeastern Jamaica, implying significant seismic hazard for the nearby capital of Kingston.

\subsection{Zone 5: Walton Fault Zone}

This is a left-lateral strike-slip fault extending southeast of the Cayman Spreading Center to the west of the Jamaican Faults with events with moderate magnitudes less than 5.1.

\subsection{Zone 6: Cayman Spreading Center}

This seismogenic source is characterized by normal fault mechanisms together with magnetic anomalies in the Cayman Through, left-lateral strike slip motion takes place at the northern end of the spreading center with moderate magnitudes less than M 6.8. Ladd et al. [28] and DeMets and Wiggins-Grandionson [26] suggest a spreading rate of $11-12 \mathrm{~mm} / \mathrm{yr}$.

\subsection{Zone 7: Hispaniola Compressional Deformation Zone}

This zone is located on the central part of Hispaniola as a part of a compression deformation and uplift due to the eastern tail of the buoyant Bahamas platform colliding obliquely with the arc in the northeastern Hispaniola and includes the Matheux-Neiba thrust fault with an estimated slip rate of $1 \mathrm{~mm} / \mathrm{yr}$.

\subsection{Zone 8: North Jamaica Margin}

Leroy et al. [29] mapped an offshore groups of faults employing both, bathymetric and magnetic anomaly identification to the north of the island of Jamaica and south of the Oriente Fault Zone, the Cliff and Marley Fracture zone have a east-west Trend, and the Cha Cha Cha, Tango Ridges and the Graper Horst are oriented with a south-west/north east direction dipping to the north-west. Moderate earthquakes had taken place in

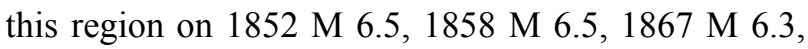
$1870 \mathrm{M} 6.1$ and $1914 \mathrm{M} 6.2$.

\subsection{Zone 9-11: Oriente Fault Zone}

This seismogenic source constitutes the boundary between the North American Plate and the Caribbean Plate as a part of the Ballet-Cayman fault system known also as the Bartlett Trough, located in the southern part of Cuba and the north of Jamaica island extending predominantly in an east to west direction in 
the Caribbean Sea constituting by far the most active tectonic feature in the region, with events having focal depths less than $50 \mathrm{~km}$. Fault plane solutions yield mainly left-lateral strike slip mechanism with some events also resulting in reverse-thrust motion. DeMets et al. [30] resolved movement along the Oriente Fault Zone off south-eastern Cuba into 18-20 mm/yr and 3 $\mathrm{mm} / \mathrm{yr}$ of convergence with highest seismicity levels in Zone 10 than Zone 11. Destructive earthquakes associated with this zone have produced seismic intensities of IX MSK at Santiago de Cuba dated on $1766 \mathrm{M} 7.6$ and $1852 \mathrm{M}$ 7.4. To the east of this seismogenic zone comprises the Septentrional Fault in the Hispaniola Island with an estimated slip rate of 12 $\mathrm{mm} / \mathrm{yr}$ (Zone 9) and strong earthquakes dated on May 7 , 1842 and September 23, 1887 with magnitudes of 7.9 and 7.6 , respectively.

\subsection{Zone 12-13: Northern Hispaniola Subduction}

Zone 12 includes an extension to the west of the Puerto Rico Trench area within depth less than $50 \mathrm{~km}$ including the megathurst faulting along the plate interface of the subducting North American Plate southward deepening and a slip rate of $2.5 \mathrm{~mm} / \mathrm{yr}$ and a maximum magnitude of 8.0 at the east of Hispaniola, however, in this updated catalogue only three earthquakes are listed as follows: April 25, 1980 M 5.0, July 8, 2004 M 5.1 and March 13, 2005 M 5.0. Zone 13 includes earthquakes with depth greater than $50 \mathrm{~km}$ in the intraplate subduction zone presented by Drapper et al. [31], in the catalogue only three earthquakes are listed on the dates July 9, 1956 M 6.40, August 9, 1971 M 5.02 and March 2, 1994 M 5.40. Seismogenic Zone 13 overlaps Seismogenic Zone 9 at the Western Part of Hispaniola Island.

\subsection{Zone 14: Cayman Ridge}

This zone constitutes a poorly defined ridge on the north side of the Cayman Spreading Center and the Cayman Trough, it is floored with a large turbudite plain and it has the appearance of a transform basin, possibly related to the opening of the basin in a north-northeast-south-southwest direction and the northern movement of Cuba during the early Cenozoic [32]. An earthquake of M 7.0 with date on June 21, 1900 is listed in the catalogue for this zone.

\subsection{Zone 15: North Cuban Fault}

Since Cuba seismogenic sources (Zone 15-17) are located more than $300 \mathrm{~km}$ away from Jamaica, in this work consideration is given only the main sources of activity in Cuba for which earthquakes be identified with magnitude above 4.5 , a detail tectonic analysis is presented by García et al. [11] employing micro seismicity data from local networks.

The seismogenic zone 15 includes the NCF (North Cuban Fault) which extends for more than 1,000 km along the northern coast of Cuba. Vertical displacements as large as $300 \mathrm{~m}$ are documented in many transverse seismic profiles along the Cuban north slope $[33,34]$. This structure is presented in the form of blocks displaced by faults with a southwest-northeast Cayman direction. This structure constitutes the limit of the interplate tectonic system, presenting a significant contrast between the northeastern border of the Cuban megablocks and the submarine depression of suture of the Old Channel of the Bahamas. The seismicity is concentrated at the intersection of the $\mathrm{NCF}$ with the major south-west-northeast-oriented faults that cut it with an estimated maximum magnitude of M 6.5 [11]. The biggest earthquakes listed in this catalogue dated on August 15, 1939 and December 28, 1998 with a magnitude of 5.6 and 5.8, respectively.

\subsection{Zone 16: Cuato-Nipe Fault}

This structure is associated with a south-north-east oriented fault system, where the Nipe-Guacanayabo and Cauto Norte faults are the principal ones. Only two earthquakes on this zone are listed in the catalogue with dates on 1551 with M 6.1 and 1624 M 6.1. García et al. [11] proposed a maximum magnitude of 7.0 for this fault. 


\subsection{Zone 17: South Cuban Shelf}

The South Cuban Shelf region is associated with new deep faults that extend for over $300 \mathrm{~km}$ all along the major part of Cuban southern coast. Only two moderate earthquakes are included in the catalogue with dates August 8, 1996 M 5.3 and October 22, 2005 M 5.1. The maximum magnitude expected in this zone is $\mathrm{M} 6.0$ [11].

\subsection{Zone 18: Pedro Escarpment}

Pindell [35] mapped the Pedro escarpment in the Caribbean Sea floor as the boundary between the Nicaragua Rise and the Colombian Basin with an orientation south west to north east dipping to the south east direction. The dominant topographic features of the northern Nicaraguan Rise are vast, shallows banks of young carbonate sediment evidently lying on continental crust, the Colombian Basin is occupied in the centre and northern part by a wide evidently thick turbidities plain which has hampered geophysical techniques and which would prevent drilling, this region is presently activated by left lateral slip and spreading. The reason for the fault boundary separating the two domains (the Nicaraguan Rise and the Colombian Basin) is not understood [35]. Only three earthquakes are listed in this region with dates on May 2, 1972 M 5.0, June 4, 1994 M 5.0 and January 22, 2010 M 5.2.

The geometrical delimitation for shallow seismicity (Fig. 2) in the arc includes the islands, related epicenters, and main geological structures such as transform faults, subduction trenches, extensional tectonic areas, spreading centers and full-apart basins. The authors list in Table 2 the main characteristics of the seismogenic zones, namely, the type, the average depth and focal mechanism of the earthquakes.

\section{Decluster of the Earthquake Catalogue}

After the compilation of the seismic catalogue, a declustering procedure was performed to remove aftershocks and foreshocks to make the seismicity consistent with the Poisson earthquake occurrence model adopted in this work. The method of Gardner and Knopoff [36] was used in the analysis, assuming that time and spatial distribution of foreshocks and aftershocks are dependent on the magnitude of the main event. After applying the algorithm, the final

Table 2 Seismogenic zone characteristics.

\begin{tabular}{lllll}
\hline Zone & Description & Type & Depth $(\mathrm{km})$ & Main focal mechanism \\
\hline 1 & Enriquillo-Plantain Garden Haiti & Crustal & 12.8 & Strike slip and thrust (inverse) \\
2 & Morant Trough & Crustal extensional & 20.0 & Normal and strike slip \\
3 & Enriquillo-Plantain Garden Jamaica & Crustal & 12.6 & Strike slip and thrust (inverse) \\
4 & Jamaican Faults & Crustal & 15.5 & Strike slip and thrust (inverse) \\
5 & Walton Fault Zone & Crustal & 11.6 & Strike slip \\
6 & Cayman Spreading Center & Crustal extensional & 14.4 & Normal and strike slip \\
7 & Hispaniola Compressional Deformation Zone & Crustal & 20.4 & Thrust (inverse) \\
8 & North Jamaican Margin & Crustal & 13.4 & Normal and strike slip \\
9 & Oriente Fault Zone A & Crustal & 9.0 & Strike slip and thrust (inverse) \\
10 & Oriente Fault Zone B & Crustal & 15.3 & Strike slip and thrust (inverse) \\
11 & Oriente Fault Zone C & Crustal & 13.8 & Strike slip and thrust (inverse) \\
12 & Northern Hispaniola Interface Subduction & Interface & 30.0 & Thrust (inverse) \\
13 & Northern Hispaniola Intraplate Subduction & Intraplate & 60.4 & Normal \\
14 & Cayman Ridge & Crustal & 17.5 & Normal and strike slip \\
15 & North Cuban Fault & Crustal & 18.2 & Thrust and strike slip \\
16 & Cuato-Nipe Fault & Crustal & 10.0 & Strike-slip \\
17 & South Cuban Shelf & Crustal & 10.0 & Normal \\
18 & Pedro Escarpment & Crustal & 22.7 & Normal and strike slip \\
\hline
\end{tabular}


catalogue contains 170 independent events with magnitude $M_{w}$ between 4.5 and 7.9 covering the years 1551-2010 (Fig. 4).

\section{The Catalogue Completeness and the Gutenberg-Richter Recurrence Relationships}

In this section, the authors address one specific aspect of quality control for the catalogue, namely the assessment of the magnitude of completeness $M_{c}$ which is defined as the lowest magnitude at which $100 \%$ of the earthquakes in a space-time volume are detected [37]. A number of methods have been applied to test the completeness of the catalogues, based on the assumption that earthquakes of magnitude greater than a stated value follow a Poisson probability distribution suggesting to de-cluster the catalogue before applying the completeness method, e.g., Refs. [36, 38].

The authors found suitable to apply the visual method of Tinti and Mulargia [39] for each seismogenic source, suggesting that the earthquakes within a magnitude interval (i.e., 5.0-5.5, 5.5-6.0, 6.0+, etc.) are complete back to a specific year if the cumulative annual numbers of events for this magnitude range are approximately linear back to that date. For example, Fig. 5 shows the completeness analysis for the Enriquillo Plantain Garden Fault SZ1 suggesting that the events in the catalogue within a magnitude bin of 5.0-5.5 are completed since the year 1985 to present. Table 3 lists the completeness periods for each magnitude bin for the seismogenic sources 1 , 3-11 employing magnitudes bins of $\Delta \mathrm{M} 0.5$. For the

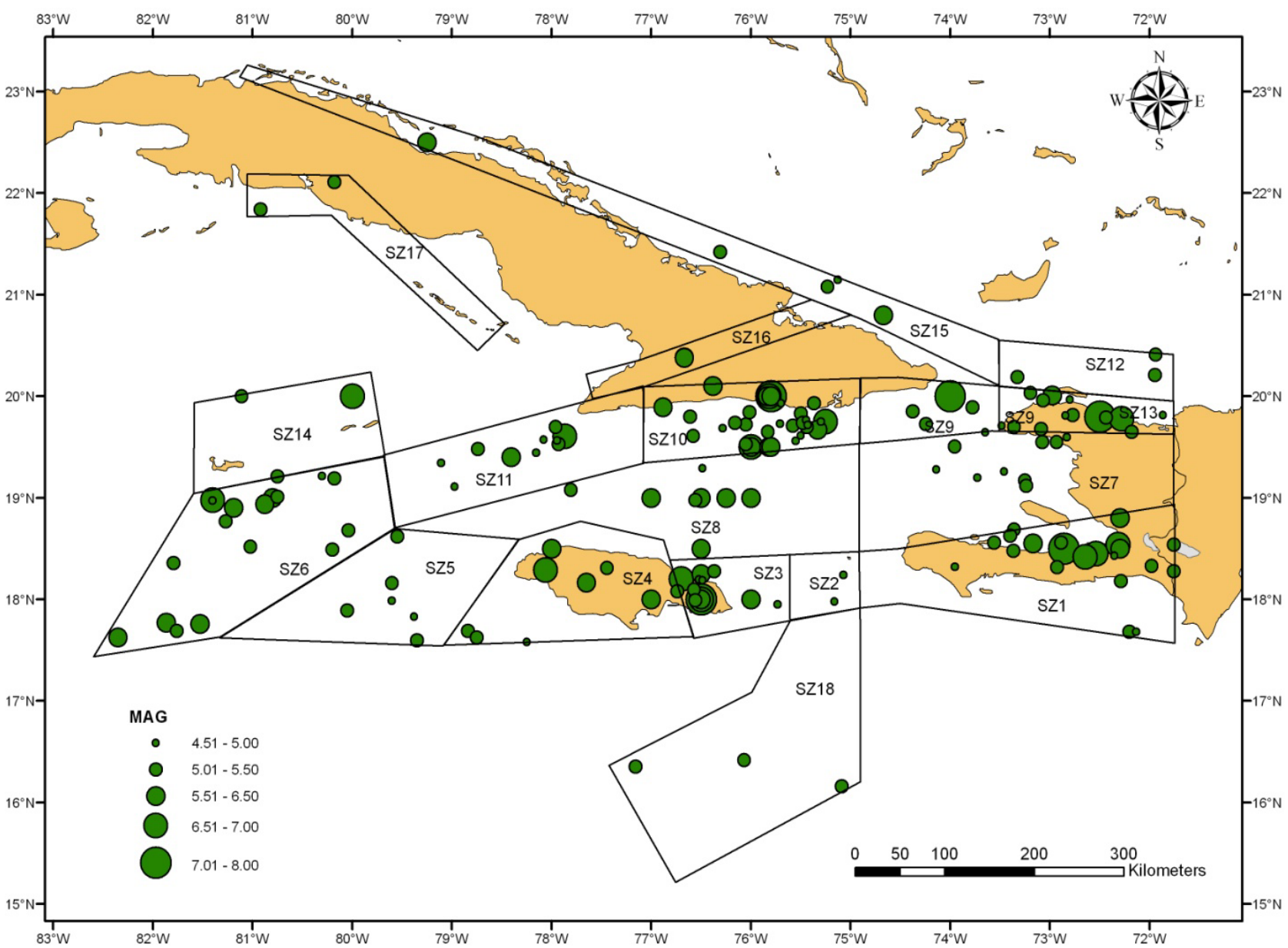

Fig. 4 Map showing the epicentres for the declustered catalogue (after removing foreshocks and aftershocks) and the delimitation of the seismogenic sources (SZ1-SZ18) for Jamaica and surrounding areas. 


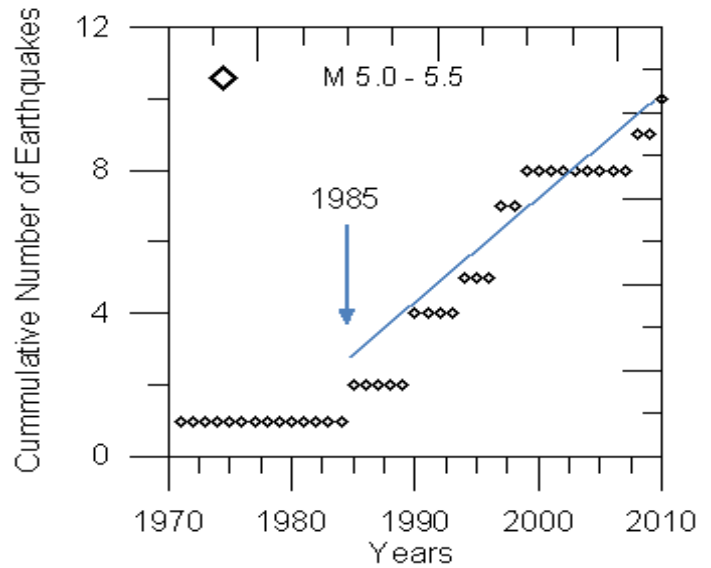

Fig. 5 Example of completeness analysis for Enriquillo Plantain Garden Fault SZ1 for a magnitude bin of 5.0-5.5 employing the method of Ref. [39] suggesting a completeness period from 1985-2010.

Table 3 Final estimate of completeness periods.

\begin{tabular}{llllllll}
\hline \multirow{2}{*}{ Zone } & \multicolumn{7}{c}{ Magnitude } \\
\cline { 2 - 8 } & 4.75 & 5.25 & 5.75 & 6.25 & 6.75 & 7.25 & 7.75 \\
\hline 1 & 1982 & 1985 & 1985 & 1798 & 1701 & 1701 & 1770 \\
3 & 1978 & 1880 & 1880 & 1824 & 1812 & 1692 & \\
4 & 1988 & 1977 & 1977 & 1943 & 1943 & & \\
6 & 1984 & 1957 & 1991 & 1962 & 1962 & & \\
8 & 2003 & 1945 & 1945 & 1852 & & & \\
9 & 2000 & 1965 & - & - & - & - & 1842 \\
10 & 1980 & 1973 & 1973 & 1682 & 1678 & 1852 & 1852 \\
11 & 2000 & 1995 & 1995 & 1992 & 1992 & & \\
\hline All Sources & 1978 & 1880 & 1880 & 1682 & 1678 & 1692 & 1770 \\
\hline
\end{tabular}

Table 4 Final estimate of completeness periods (Zone 5-7).

\begin{tabular}{lllllll}
\hline \multirow{2}{*}{ Zone } & \multicolumn{6}{c}{ Magnitude } \\
\cline { 2 - 7 } & 4.6 & 4.8 & 5.1 & 4.63 & 4.88 & 5.1 \\
\hline Zone 5 & 2005 & 2004 & 1977 & - & - & - \\
Zone 7 & - & - & - & 2005 & 1955 & 1973 \\
\hline
\end{tabular}

seismogenic sources 5 and 7 a small magnitude bin $\Delta \mathrm{M}$ of 0.20 and 0.25 were used respectively due to the limited amount of data for small magnitudes (Table 4).

In the attainment of a Gutenberg-Richter (G-R) recurrence relationship characterizing the regional seismicity the expression is adopted below:

$$
\log _{10}(N)=A-B M
$$

where, $N$ represents the cumulative number of earthquakes above magnitude $M$, and $A$ and $B$ set two constants derived from regression analysis. Constant $B$ is the measure of the relative abundance of large to small shocks. Table 5 lists the $A$ and $B$ recurrence values and the seismicity parameters $\beta(2.303 B), v$ (mean annual rate for the minimum magnitude of 4.5) and observed maximum magnitude $M_{\max }$ for each seismogenic source in the catalogue. Also, a $M_{\max 2}$ equal to $M_{\operatorname{maxl}}$ plus 0.5 units is considered in the hazard assessment. The number of earthquakes within different magnitudes ranges has been computed using the bounded G-R relationship based on Ref. [40] relationships. The authors were not able to develop for some seismogenic sources $(2,12-18)$ G-R due to the lack of data, in this cases, a pure characteristic model was adapted calculating the activity rate (number of earthquakes per year) and setting the Characteristic Magnitude 1 as the medium value for the magnitude bin employed to count such events (Table 6). A Characteristic Magnitude 2 is considered also in the seismic hazard with an increment of 0.5 or 1.0 units of the Characteristic Magnitude 1 (Table 6).

\section{GMPE's (Ground Motion Prediction Equations)}

The GMPE's are regionally dependent and the choice of appropriate relations depends on the tectonic environment around the site of interest. No specific GMPE's have been developed for Jamaica and surrounding areas. In order to be compatible with the tectonic environment of the region, the state of the art GMPE's was employed to compute the seismic hazard:

(1) For crustal zones: Sadigh et al. [41]; Kanno et al. [42]; Zhao et al. [43]; Abrahamson and Silva [44]; Chiou and Youngs [45];

(2) For subduction zones: Youngs et al. [46]; Atkinson and Boore [47]; Zhao et al. [43]; Kanno et al. [42]; Lin and Lee [48].

Details of the formulation of each GMPE's can be found in the original articles cited in the reference section of this report. To incorporate the GMPE's in the PSHA computation, the closest distance to the rupture surface was used, since it is the common distance definition amongst the GMPE's with the exception for 
Table 5 Seismicity evaluation parameters for G-R model: $\beta$ is equal to $2.303 B$ and $v$ denotes the activity rate for the minimum magnitude 4.5, $M_{\max 1}$ : maximum historical magnitude; $M_{\max 2}$ : $M_{\max 1}$ plus 0.5 units.

\begin{tabular}{|c|c|c|c|c|c|c|c|}
\hline Zone & Description & $A$ & $B$ & $\beta$ & $v$ & $M_{\max 1}$ & $M_{\max 2}$ \\
\hline 1 & Enriquillo-Plantain Garden & 3.19 & 0.73 & 1.68 & 0.80 & 7.5 & 8.0 \\
\hline 3 & Enriquillo-Plantain Garden Jamaica & 2.13 & 0.61 & 1.41 & 0.24 & 7.4 & 7.9 \\
\hline 4 & Jamaican Faults & 2.82 & 0.64 & 1.47 & 0.87 & 6.6 & 7.1 \\
\hline 5 & Walton Fault Zone & 5.27 & 1.21 & 2.79 & 0.67 & 5.1 & 5.6 \\
\hline 6 & Cayman Spreading Center & 1.88 & 0.45 & 1.04 & 0.72 & 6.8 & 7.3 \\
\hline 7 & Hispaniola Compressional Deformation Zone & 5.98 & 1.30 & 2.99 & 1.35 & 5.3 & 5.8 \\
\hline 8 & North Jamaican Margin & 2.68 & 0.67 & 1.54 & 0.46 & 6.5 & 7.0 \\
\hline 9 & Oriente Fault Zone A & 2.17 & 0.53 & 1.22 & 0.61 & 7.9 & 8.4 \\
\hline 10 & Oriente Fault Zone B & 4.09 & 0.86 & 1.98 & 1.66 & 7.4 & 7.9 \\
\hline 11 & Oriente Fault Zone C & 2.08 & 0.46 & 1.05 & 1.02 & 6.8 & 7.3 \\
\hline
\end{tabular}

Table 6 Seismicity evaluation parameters for pure characteristic models, (*) Activity rate for zone 12 [21].

\begin{tabular}{lllll}
\hline Zone & Description & $\begin{array}{l}\text { Activity rate } \\
\text { (earthquake/year) }\end{array}$ & $\begin{array}{l}\text { Characteristic } \\
\text { Magnitude 1 }\end{array}$ & $\begin{array}{l}\text { Characteristic } \\
\text { Magnitude 2 }\end{array}$ \\
\hline 2 & Morant Trough & 0.14300 & 4.8 & 5.3 \\
$12^{*}$ & Interface Northern Hispaniola Subduction & 0.00088 & 7.5 & 8.0 \\
13 & Intraplate Northern Hispaniola Subduction & 0.05130 & 5.9 & 6.4 \\
14 & Cayman Ridge & 0.01800 & 6.0 & 7.0 \\
15 & North Cuban Fault & 0.03300 & 5.8 & 6.3 \\
16 & Cuato-Nipe Fault & 0.02700 & 6.3 & 6.8 \\
17 & South Cuban Shelf & 0.20000 & 5.3 & 5.8 \\
18 & Pedro Escarpment & 0.07690 & 5.3 & 5.8 \\
\hline
\end{tabular}

Lin and Lee [48] subduction zones that used the hypocentral distance. A source-to-site distance conversion algorithm based on simulated data and gamma distribution models has been proposed to convert, i.e., the hypocentral distances to the closest distance to rupture surface [49], however, this algorithm is applicable for shallow earthquakes up to magnitudes 7.5 and distances between $0-100 \mathrm{~km}$. Due to that the subduction zones 13 and 14 are located about $450 \mathrm{~km}$ away from Jamaica, the use of either the hypocentral and closest distance to rupture surface would have small influences in the results for the characteristic magnitudes employed in the hazard analysis, the option to use the hypocentral distance definition for the GMPE's of Lin and Lee [48] was done.

\section{Probabilistic Seismic Hazard Assessment for Jamaica}

\subsection{Standard Cornell-McGuire Approach}

The seismotectonic setting of Jamaica and surrounding areas has been carefully examined in the previous section in order to identify and establish the delimitation of appropriate seismogenic sources, which constitutes the fundamental input data for the standard Cornell-McGuire approach. After the compilation of the earthquake catalogue, declustering has been carried out to remove aftershocks and foreshocks in order to make the earthquake catalogue consistent with the earthquake occurrence model adopted in the classical Cornell-McGuire approach, namely the Poissonian probability distribution for which the occurrence of an event is independent of others events in the catalogue. Subsequently, the completeness analysis of the declustered catalogue was performed for earthquakes pertaining to each of the identified seismogenic sources to define the Gutenberg-Richter recurrence parameters. The authors have associated for each seismogenic zone a GMPE's according with the correspondent tectonic regime.

The standard Cornell-McGuire approach solves the 
following equation:

$$
E(z)=\sum_{i=1}^{N s} v_{i} \int_{r=0}^{\infty} \int_{M_{\min }}^{M_{\text {max }_{i}}} f_{m_{i}}(m) f_{r_{i}}(r) P(Z>z \mid m, r) d r d m
$$

where,

$E(z)=$ mean annual rate of exceedance of ground motion level " $z$ " during a specified time period " $t$ ";

$N s=$ number of seismogenic sources;

$v_{i}=$ mean rate of occurrence of earthquakes between lower/upper bounds magnitude " $m$ " being considered for the " $i$ "

$f_{m i}(m)=$ probability density distribution of magnitude within the " $i$ " " source, which is obtained using the Gutenberg-Richter relationship;

$f_{r i}(r)=$ probability density distribution of epicentral distance " $r$ " between various locations within source " $i$ "th" and the site where hazard is estimated;

$P(Z>z \mid m, r)=$ probability that a given earthquake of magnitude " $m$ " and epicentral distance " $r$ " will exceed ground motion level " $z$ ", which is obtained employing the selected attenuation relationships.

Seismic hazard assessment involves the production of contour maps that represent the levels of ground shaking expected to be experienced over a particular return period. The probability of exceedence $q$ that there would be one or more events within a lifetime (in years) of the structures $L$ can therefore be expressed as:

$$
q=1-e^{-L E(z)}
$$

where, $1 / \mathrm{E}(\mathrm{z})$ is the return period $T$ for a specific ground motion. Probability levels calculated can vary from $50 \%$ to $10 \%$ (most common) to $2 \%$ over a period of 50 years lifetime. The most widespread measure of earthquake hazard is therefore one which shows the probability (as a percentage) of a particular level of horizontal ground acceleration (usually PGA) being experienced for an event that occurs every 475 year return period ( $10 \%$ probability in 50 years life time). However, spectral ordinates are also used to represent the hazard usually for periods $0.2 \mathrm{~s}$ and $1.0 \mathrm{~s}$ in accordance to the IBC. The authors employed in this work the computer program EZ-FRISK $® 7.62$ for the Cornell-McGuire zone method.

\subsection{Free-Zone Method}

The zone-free method proposed by Woo [13] has been applied as an alternative approach to the Cornell-McGuire method in the seismic hazard analysis [50]. This method removes uncertainties inherent in the definition of seismogenic zones. The hazard solely reflects the characteristics of the earthquake catalogue. The zone-free approach is also called the kernel estimation method since it implements spatial smoothing of seismicity. In this method seismic sources are not defined according to geological and tectonic criteria. A magnitude-dependent, probabilistic smoothing procedure is applied directly to earthquake epicenters of the catalogue to construct the source model. Therefore, the kernel-smoothed epicenters depict the spatial non-uniformity of seismicity in contrast to the rigid zonation in the Cornell-McGuire approach which assumes that seismicity is uniformly distributed within each seismogenic zone.

A grid of point sources (nodes) is defined about the site of interest with relative activity rates determined according to the earthquake catalogue. The contribution of each earthquake to the seismicity of the region is smeared over a distance that is magnitude dependent. Instead of defining the activity rate of each source using a recurrence relationship, such as the Gutenberg-Richter equation, individual rates for each magnitude bin are calculated from the density and proximity of the catalogued events lying within that magnitude bin. To do so the Woo [13] method uses concepts from fractal geometry.

The magnitude-distance dependent relationship is given by the kernel function $K$, which is a multivariate probability density function, expressed by the following equation:

$$
K=\frac{n-1}{\pi H^{2}}\left[1-\left(\frac{r}{H}\right)^{2}\right]^{-n}
$$

where, $r$ is the epicentral distance, $n$ is an exponent which increases with the proximity of epicenters. Its 
value is typically between 1.5 and 2 , and it has only a moderate influence on the computed results. $H$ is the bandwidth for normalizing epicentral distances and is a function of magnitude. It represents the average minimum distance between epicenters of the same magnitude class and takes the following exponential form:

$$
H=c e^{d M}
$$

where, $c$ and $d$ are constants to be determined on the basis of the location of the epicenters of the catalog and $M$ is the moment magnitude. In this work, a special bandwidth for Jamaica and surrounding areas was generated employing the earthquake catalogue developed in the previous section (Fig. 6) and partitioned the events in the catalogue into magnitudes bins of $\Delta \mathrm{M}=0.5$. The kernel function allows the influence of magnitude to vary with distance. This accounts for the observation that smaller events exhibit a greater amount of spatial clustering than larger events, suggesting that small events are more likely than large events to occur in places where they have occurred in the past [13].

By summing over all events, the cumulative activity rate density is computed for each magnitude class, from the minimum magnitude of engineering interest (here taken to be 4.5) to the maximum magnitude of the catalogue. Once the activity rate of each magnitude class has been defined for each point source in the mesh, a GMPE is employed and the hazard is calculated by summing over each point source as in the Cornell-McGuire method. The authors employed a grid mesh of $50 \mathrm{~km} \times 50 \mathrm{~km}$ for the whole region of study taken as the average distance observed in the smoothing function for the minimum magnitude class M 4.5-5.0 in the fractal geometry (Fig. 6), taking into account two background seismicity magnitudes and their annual frequency of occurrence based on the maximum magnitudes values in the catalogue within a circular area of $300 \mathrm{~km}$ radius around Jamaica increased by 0.25 and 0.5 yielding a M 7.65 and 7.9 respectively. The associated annual frequencies of occurrence for these magnitudes are found using the G-R constants relationships listed in Table 5, using an average depth of $13.3 \mathrm{~km}$ for the entire region based on the reported depth for the shallow events in this catalogue. Noted that only three events with $\mathrm{M}<5.5$ and depth greater than $50 \mathrm{~km}$ are reported in the catalogue at a distance of about $400 \mathrm{~km}$ for Jamaica; these events were excluded from the computation, then the authors took into account only shallow crustal earthquakes for the free-zone method.

The Kernel method has been applied to the Jamaican region using a modified version of the original numerical FORTRAN code KERFRACT developed by Woo (1996) and used in another Central American PSHA's [51].

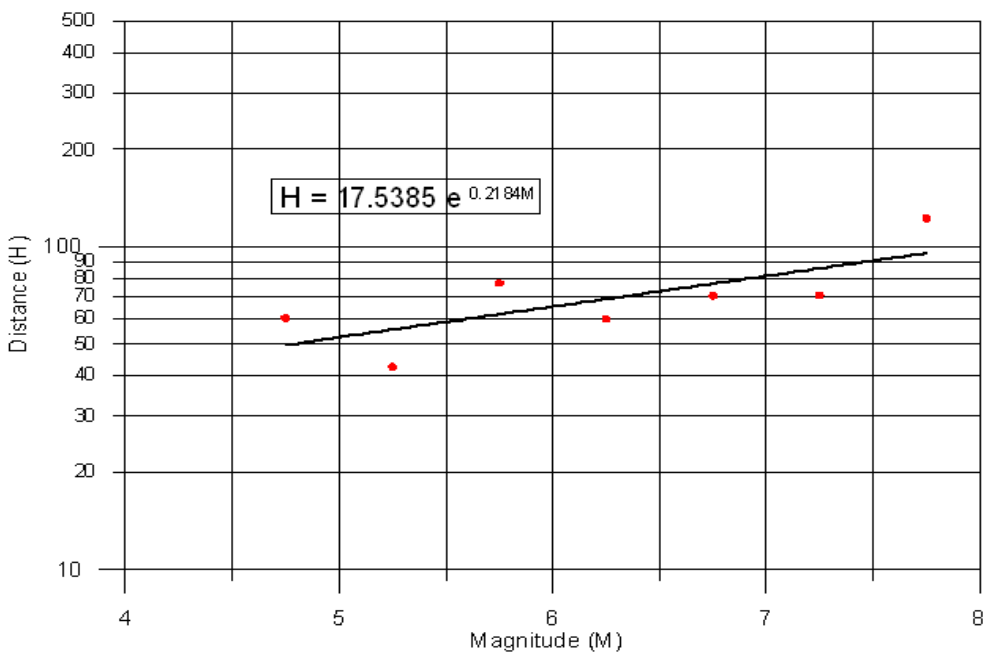

Fig. 6 Bandwidth for normalizing epicentral distances for Jamaica and surrounding areas. 
Since the zone-free method is not based on a Poissonian model of earthquake recurrence, the entire catalogue which includes both foreshocks and aftershocks may be used in the hazard computation. Uncertainties in magnitude and epicenter location and effective historical period of observation need to be introduced in the method. The uncertainties assumed in earthquake magnitude and locations are summarized in Tables 7 and 8, after Bozzoni et al. [50]. Another parameter requested by the zone-free approach is the effective historical period of observation. In this study, it has been taken equal to the completeness period computed using all the events of the entire region (Tables 3 and 4).

\subsection{Logic Tree Formulation}

Epistemic uncertainties in the hazard assessment have been addressed in a logic-tree framework by considering the following parameters: (1) the PSHA algorithms (Cornell-McGuire and zone-free approaches); (2) the maximum cutoff magnitudes; and (3) the GMPEs.

The logic tree for the horizontal component consists of a total of 12 branches (Fig. 7): 10 branches are associated to the Cornell-McGuire approach (five GMPE's by two maximum magnitudes), while the remaining two branches refer to the zone-free approach. Equal weights have been assigned to the two different maximum magnitudes, since there is no reason to prefer one alternative over the other. Concerning GMPEs, equal weights have been associated with GMPEs since no strong motion data are available for Jamaica. Each seismogenic zone in the Cornell-McGuire method has been treated separately: all the branches for each seismogenic zone have been weighted averaged to obtain a mean hazard curve for each seismogenic zone. The 18 mean hazard curves (1 $\times 18$ seismogenic zones) have then been summed at each site to produce a single hazard curve representing the Cornell-McGuire final computation. The logic tree is therefore composed by two main branches: one refers to the Cornell-McGuire method (with weight
$0.50)$ and the other refers to the zone-free approach (with weight 0.50 ). It is noted that while Kanno et al. [42] GMPE's are formulated for all types of earthquakes, the Zhao et al. [43] formulation differentiate the ground motion and the spectral ordinates estimation between different focal mechanisms, in this case equally weighting the strike-slip and the thrust faulting in the hazard scheme as these are the predominant focal mechanisms for shallow earthquakes. The KERFRACT CODE was modified to take into account automatically such possibility in one running.

\subsection{Results}

Seismic hazard results are presented in terms of hazard maps and uniform hazard spectral accelerations for the horizontal component, calculated for: stiff ground conditions (NEHRP site classification B) and flat topographic surface representing outcropping ground conditions:

(1) $5 \%$ structural damping of the critical;

(2) five return periods RP $(95,475,975,2,475$, 4,975 years);

(3) 34 spectral periods (from 0 to $3 \mathrm{~s}$ );

(4) 874 computational points corresponding to a resolution of a spatial grid of 0.050 degrees with an average spacing of the nodes of about $5.5 \mathrm{~km}$;

Table 7 Uncertainties $\sigma$ in the estimate of magnitude used in the kernel estimation method [50].

\begin{tabular}{ll}
\hline Type of magnitude and year & Magnitude $(\sigma)$ \\
\hline All magnitudes (1551-1899) & 0.50 \\
All magnitudes (1900-1974) & 0.25 \\
$M_{W}(1975-2010)$ & 0.10 \\
$M_{S}(1975-2010)$ & 0.15 (see Fig. 1) \\
$m_{b}(1975-2010)$ & 0.24 (see Fig. 1) \\
\hline
\end{tabular}

Table 8 Uncertainties $\sigma$ in the estimate of epicentral distance used in the kernel estimation method [50].

\begin{tabular}{ll}
\hline Year & Distance $(\sigma)(\mathrm{km})$ \\
\hline $1551-1899$ & 30 \\
$1900-1963$ & 20 \\
$1964-1975$ & 10 \\
$1976-2010$ & 5 \\
\hline
\end{tabular}




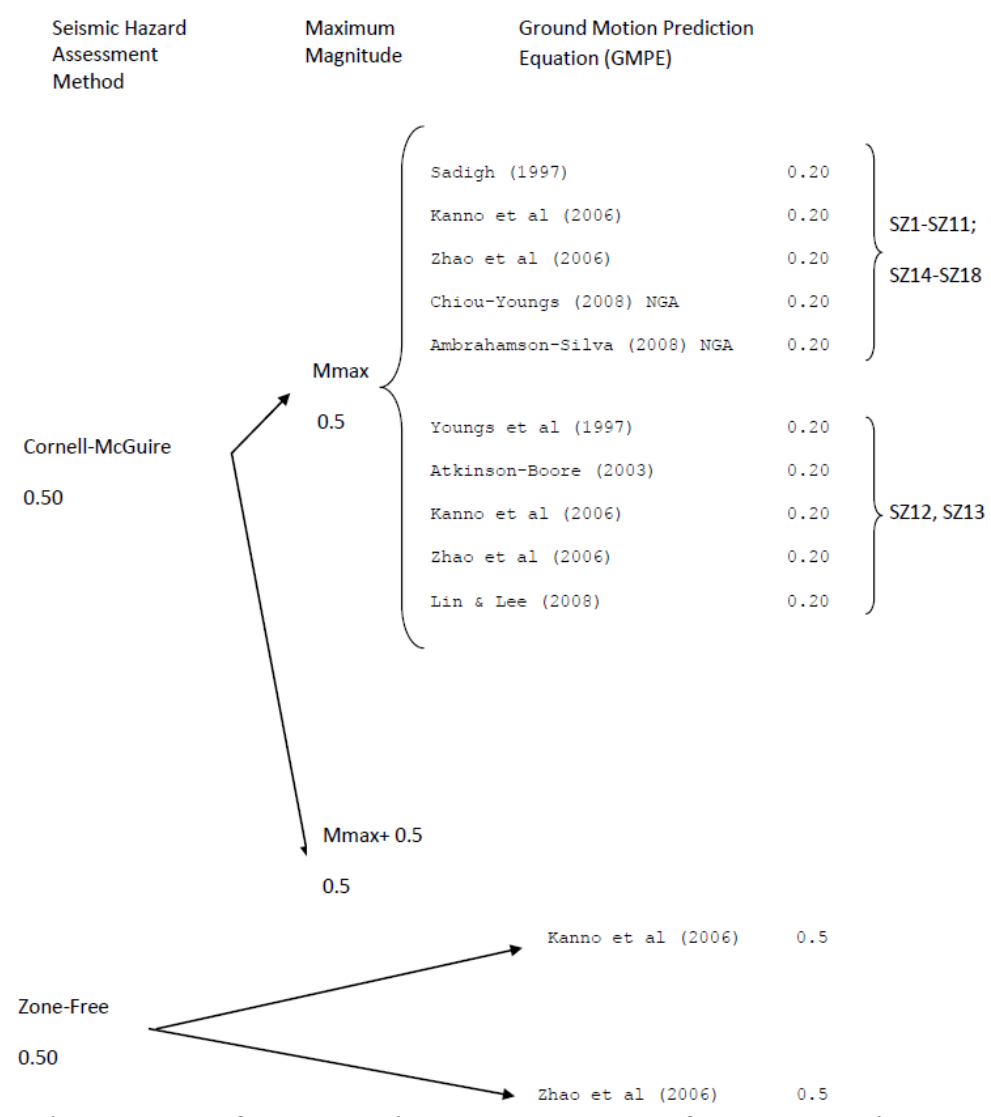

Fig. 7 Logic-tree formulation adopted for the horizontal component of ground motion, the weights used in hazard calculations corresponds to the numbers written to the right and the bottom of each branch of the Logic-Tree, SZ1-SZ18 denotes the seismogenic zones.

(5) a truncation value of 3 sigma $(3 \sigma)$ in the GMPE's.

Figs. 8-12 show the seismic hazard contour maps and their uncertainties developed for Jamaica in terms of PGA with $10 \%$ probability of exceedence in 50 years $(\mathrm{RP}=475$ years), $\mathrm{SA}$ at 0.2 and $1.0 \mathrm{~s}$ with $2 \%$ and $1 \%$ probability of exceedence in 50 years $(\mathrm{RP}=$ 2,475 and 4,975 years). PGA with $\mathrm{RP}=475$ years has been considered since it is the widely used parameter to express the results of PSHA, while the computing of the spectral acceleration at periods of $0.2 \mathrm{~s}$ and $1.0 \mathrm{~s}$ and $\mathrm{RP}=2,475$ and 4,975 years is consistent with International Building Codes [12, 52].

The uncertainties are presented in terms of the $\mathrm{COV}$ (coefficient of variation) [53] and are illustrated in Figs. 8-12. The COV is the standard deviation of the estimated PGA or SA at each point divided by the mean value at that point $(\mathrm{COV}=\sigma / \chi)$ and tells you the relative breath of the Gaussian distribution used to represent the variability for all branches in the logic tree.

The COV for the PGA varies for 0.1 to 0.3 inland Jamaica, with the higher values above 0.3 offshore. The COV decreases substantially for the SA of $0.2 \mathrm{~s}$ varies from 0.08 to 0.20 , with the higher values near the area with the highest hazard level to the east of the island; in other words there are variations of $10 \%$ to $30 \%$ and $0.8 \%$ to $20 \%$ in ground motion and acceleration spectral ordinates. The similar case is found for the SA of $1.0 \mathrm{~s}$, the COV yields 0.1 to 0.26 , this observation states that despite the seismic coefficient induced by earthquakes in the long period range could be low in certain areas, it can produce damage in long period structures due to the uncertainty of the level shaking, in fact, the standard deviation associated with long period components in the GMPE's is larger than the ones obtained for short period 


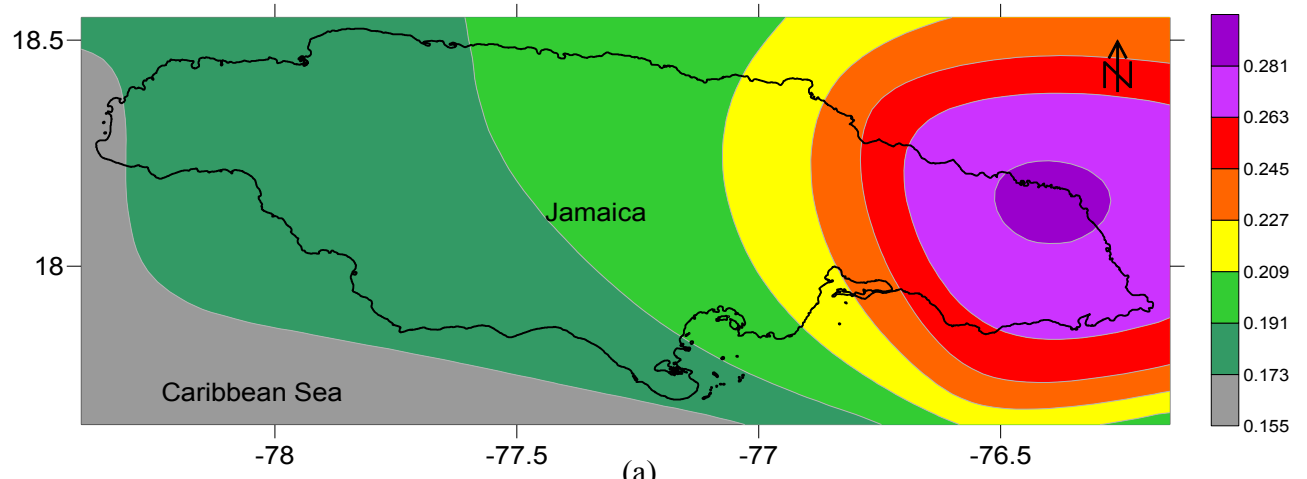

(a)

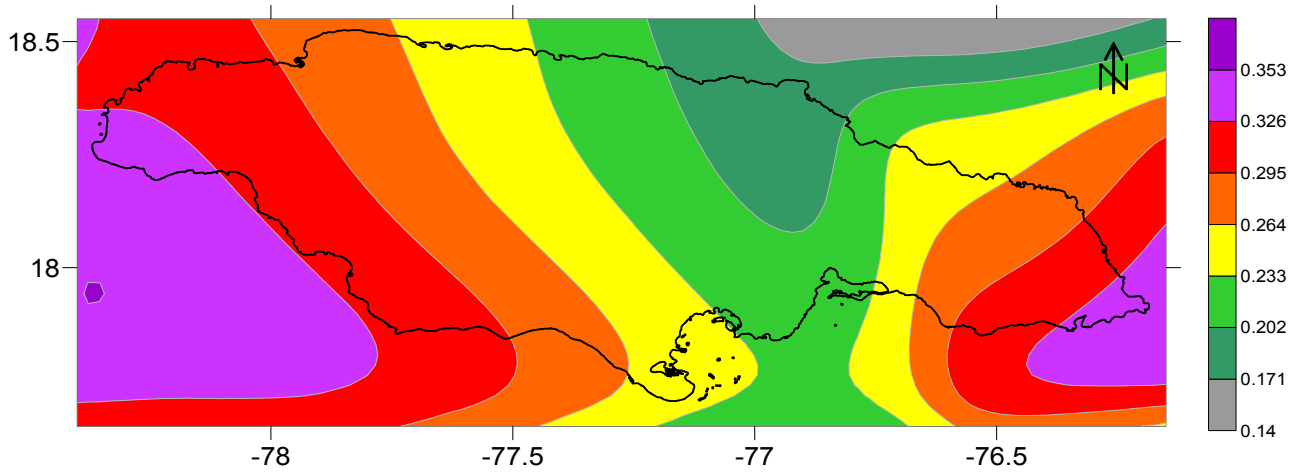

(b)

Fig. 8 The seismic hazard contour maps and their uncertainties: (a) seismic hazard map for the peak ground acceleration (g) and 475 years return period; (b) acceleration uncertainties in terms of covariance.
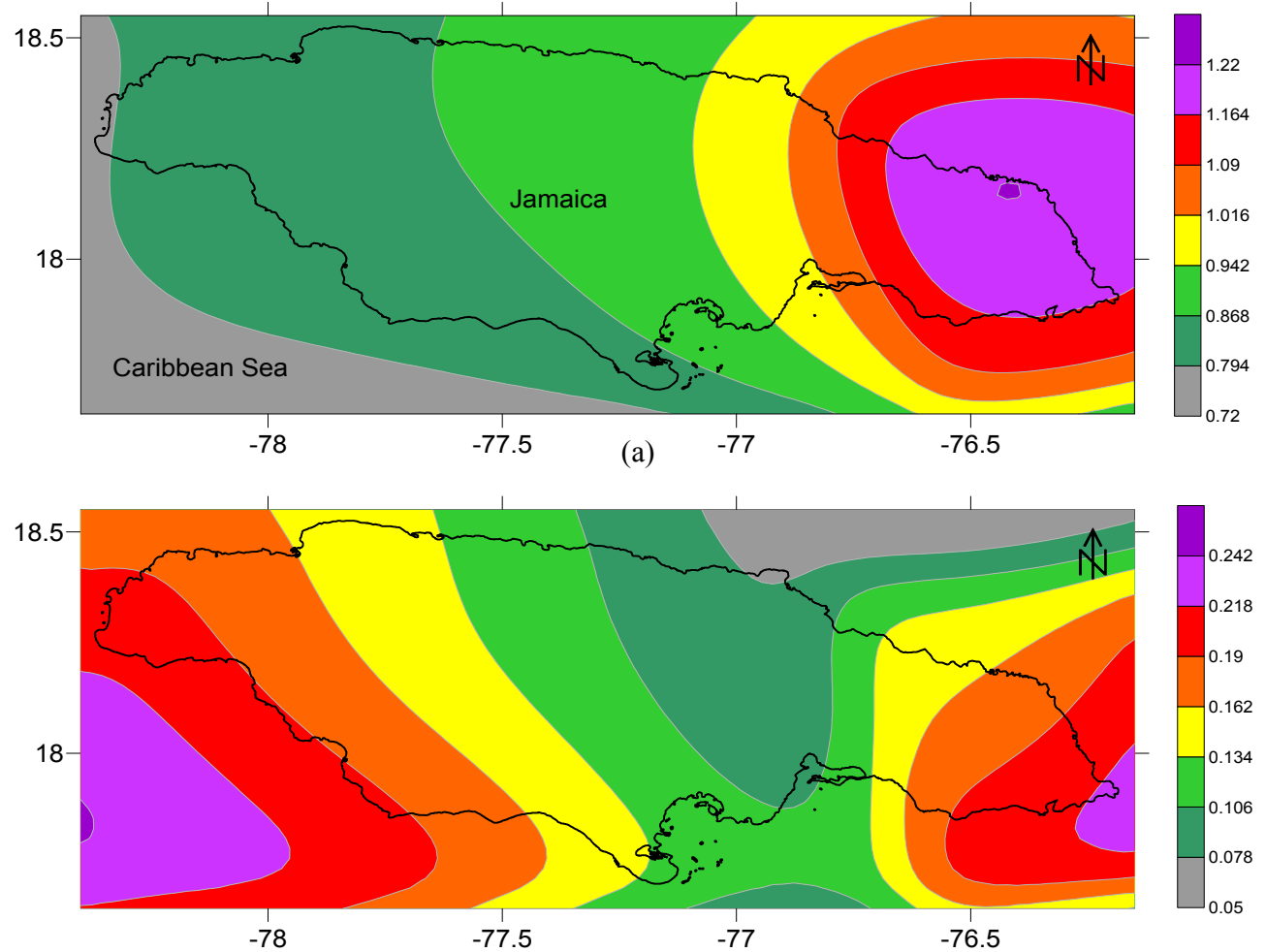

(b)

Fig. 9 The seismic hazard contour maps and their uncertainties: (a) seismic hazard map for spectral acceleration (g) at the period of $0.2 \mathrm{~s}$ and 2,475 years return period; (b) acceleration uncertainties in terms of covariance. 
18.5
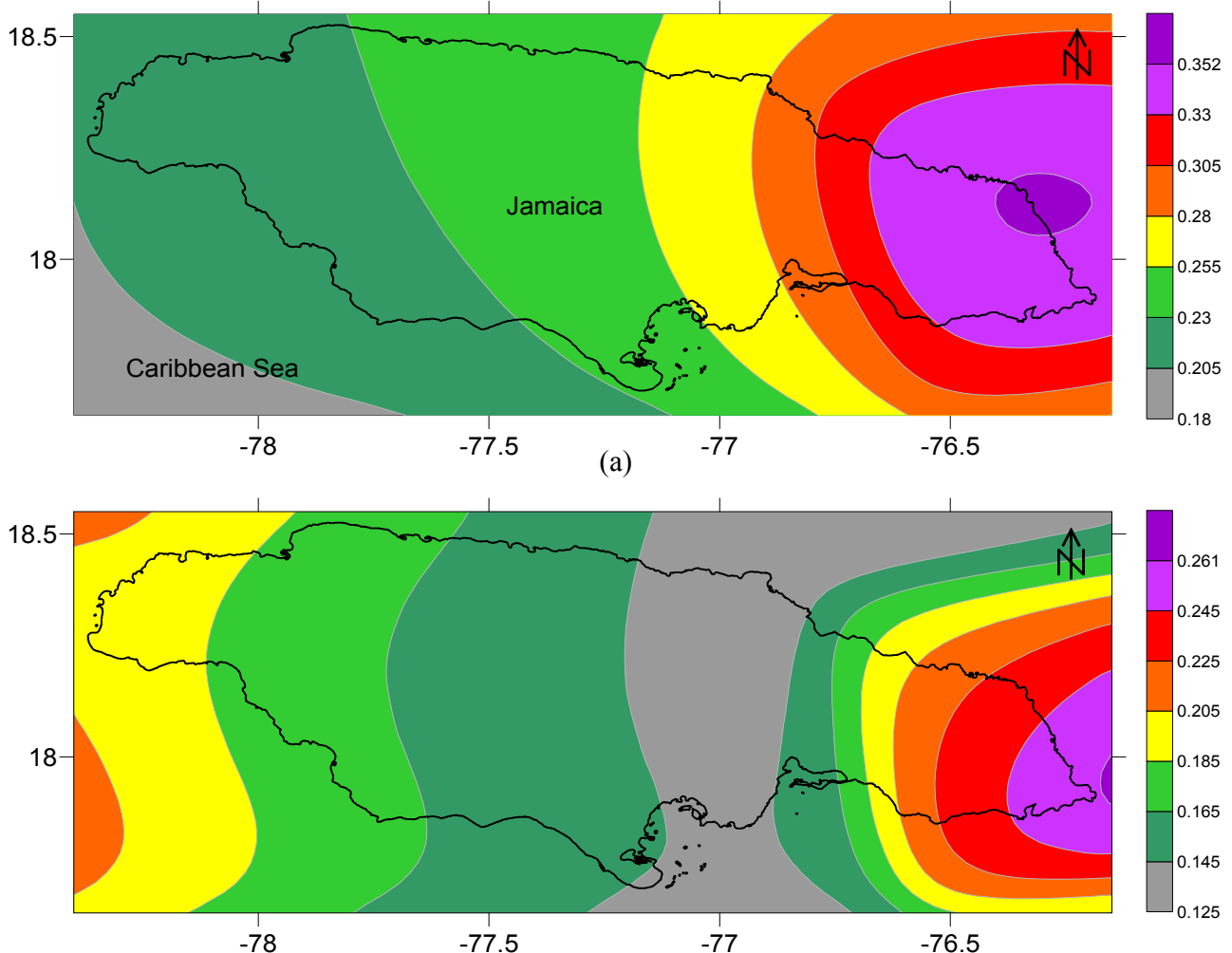

(b)

Fig. 10 The seismic hazard contour maps and their uncertainties: (a) seismic hazard map for spectral acceleration (g) at the period of $1.0 \mathrm{~s}$ and 2,475 years return period; (b) acceleration uncertainties in terms of covariance.

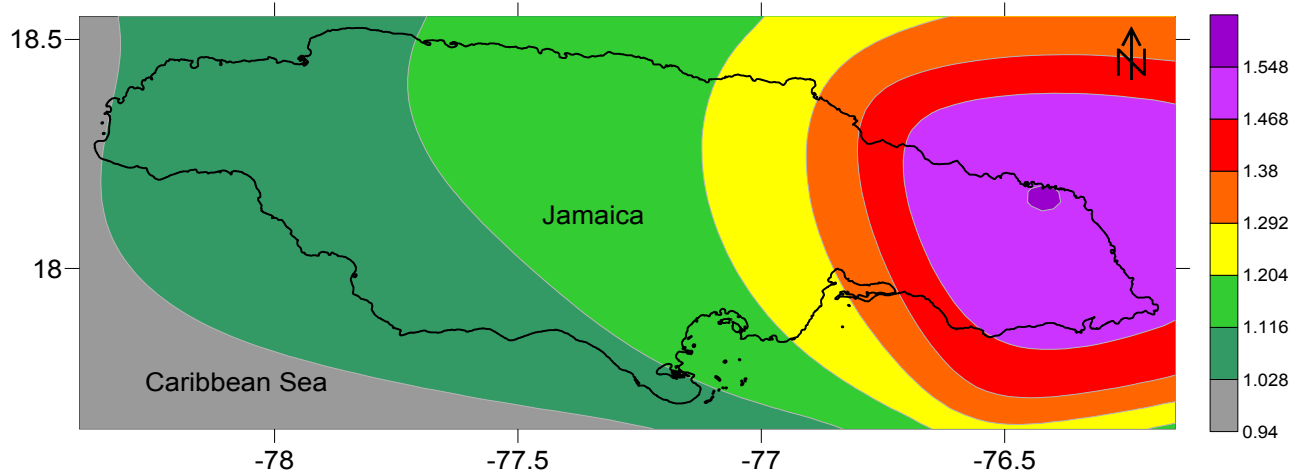

(a)

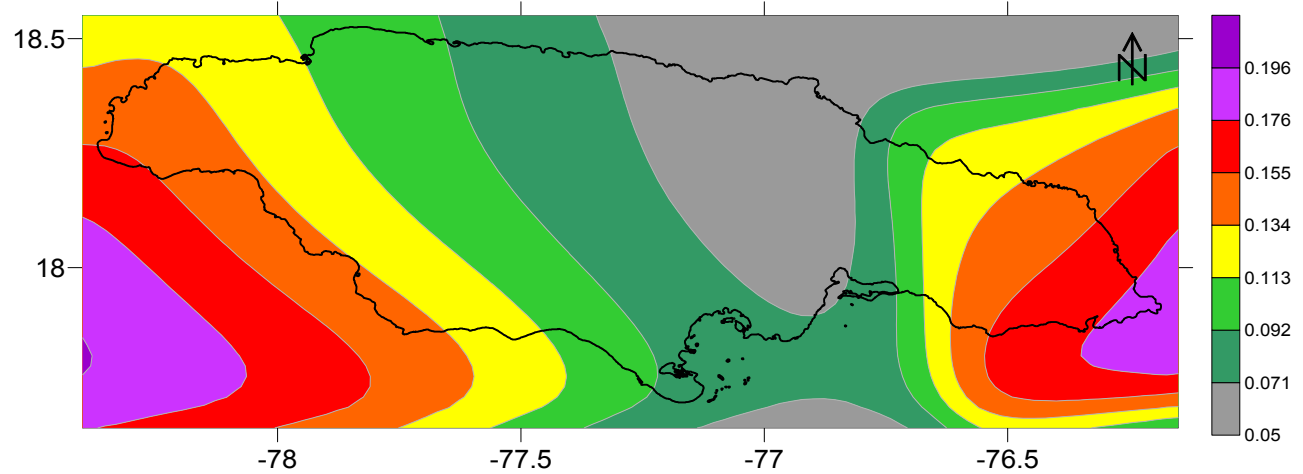

(b)

Fig. 11 The seismic hazard contour maps and their uncertainties: (a) seismic hazard map for spectral acceleration (g) at the period of $0.2 \mathrm{~s}$ and 4,975 years return period; (b) acceleration uncertainties in terms of covariance. 

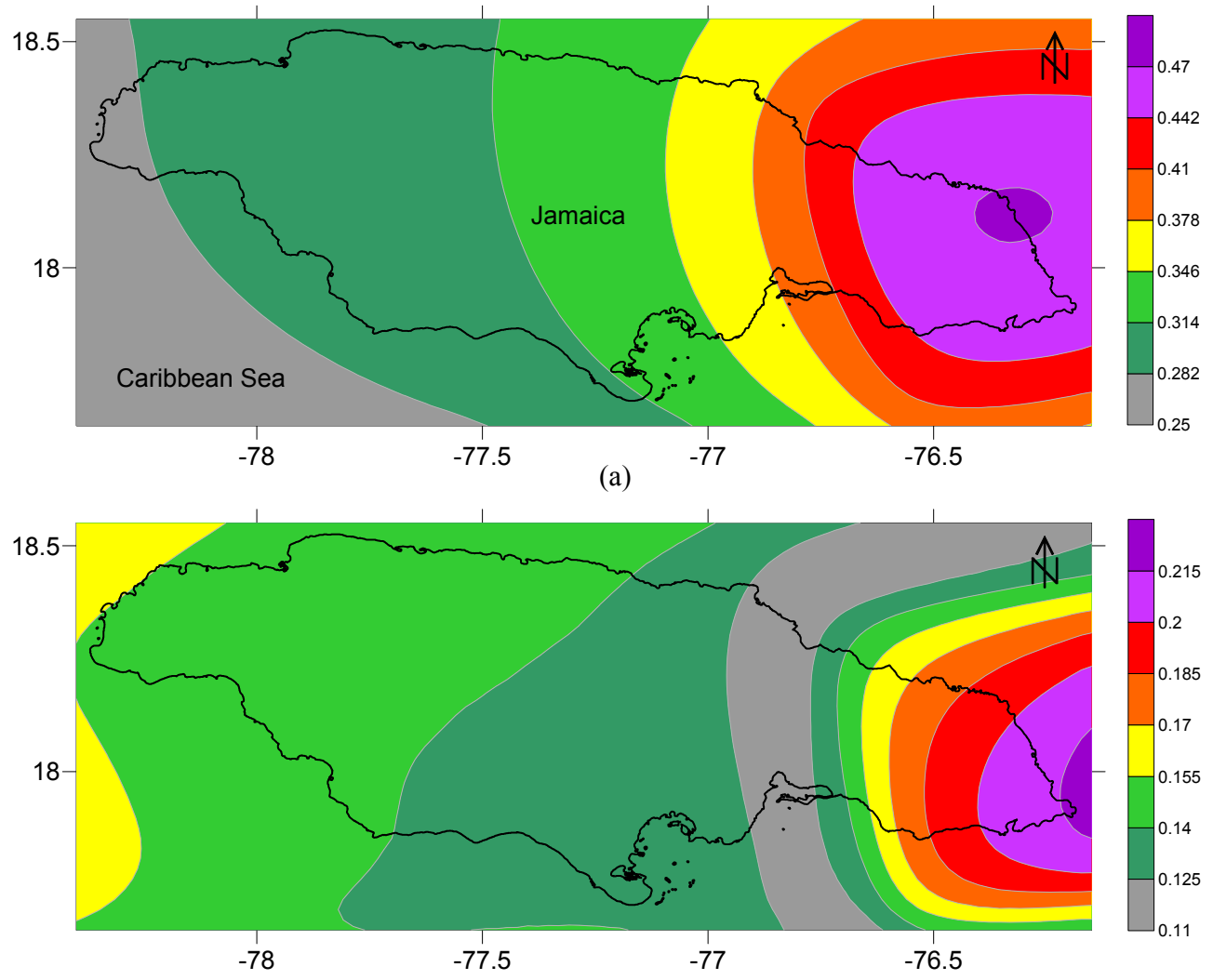

(b)

Fig. 12 The seismic hazard contour maps and their uncertainties: (a) seismic hazard map for spectral acceleration (g) at the period of $1.0 \mathrm{~s}$ and 4,975 years return period; (b) acceleration uncertainties in terms of covariance.

Table 9 Degree of reliability for different values of covariance COV.

\begin{tabular}{ll}
\hline Covariance COV & Degree of reliability \\
\hline $0 \leq v<10 \%$ & Very high \\
$10 \leq v<20 \%$ & High \\
$20 \leq v<30 \%$ & Medium \\
$30 \leq v<40 \%$ & Low \\
$v \geq 40 \%$ & Very low \\
\hline
\end{tabular}

components. The degree of reliability of our COV estimations is classified as high/very high for spectral ordinates (SA) from high/medium for the PGA (Table 9). This aspect is very important to justify the use of the spectral ordinates for $0.2 \mathrm{~s}$ and $1.0 \mathrm{~s}$ to construct the earthquake design response spectra according to the IBC code regulations.

The elastic response spectra is presented in Fig. 13 for KMA (Kingston metropolitan area) with a $5 \%$ of critical damping for the five return periods under consideration and 34 structural periods ranging from $0 \mathrm{~s}$ (PGA) to $3 \mathrm{~s}$.

Fig. 14 shows the influence of the various models of seismic sources to the overall hazard for the site representative of KMA. The considered source models are the individual seismogenic zones in case of the Cornell-McGuire approach and the case of the zone-free approach (Fig. 14). Hazard is expressed in terms of hazard curves referred to the PGA. The resulting curves, given by the sum of the hazard curves associated with the individual source models, are shown as well. Concerning seismogenic zones, Fig. 14 shows that Zone 3 and 4, which constitutes the Plantain Garden Fault and the Jamaican Faults seismogenic zones, dominates the hazard in Kingston. However, the SZ8 (North Jamaican Fault) and SZ10 (Oriente Fault zone) substantially contributes to the hazard. A good matching is observed for the free zone method when using the GMPE's [42, 43].

A comparison between the UHS (uniform hazard spectrum) computed for KMA (Kingston metropolitan area) for $\mathrm{RP}=2,475$ and 4,975 years and the design 


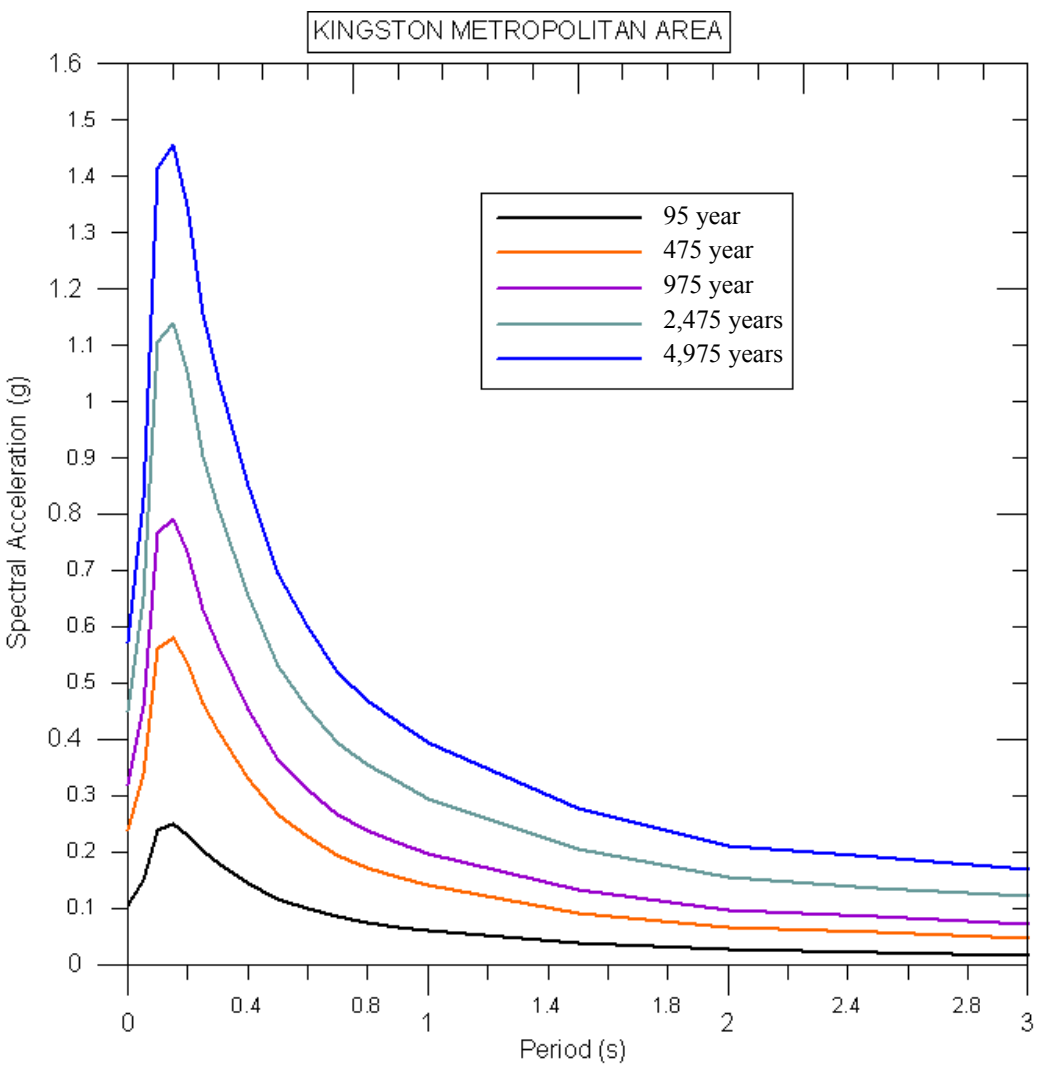

Fig. 13 Design elastic response spectra for $5 \%$ of critical damping for Kingston metropolitan $\operatorname{area}\left(18^{\circ} \mathrm{N}, \mathbf{7 6 . 8}^{\circ} \mathrm{W}\right)$.
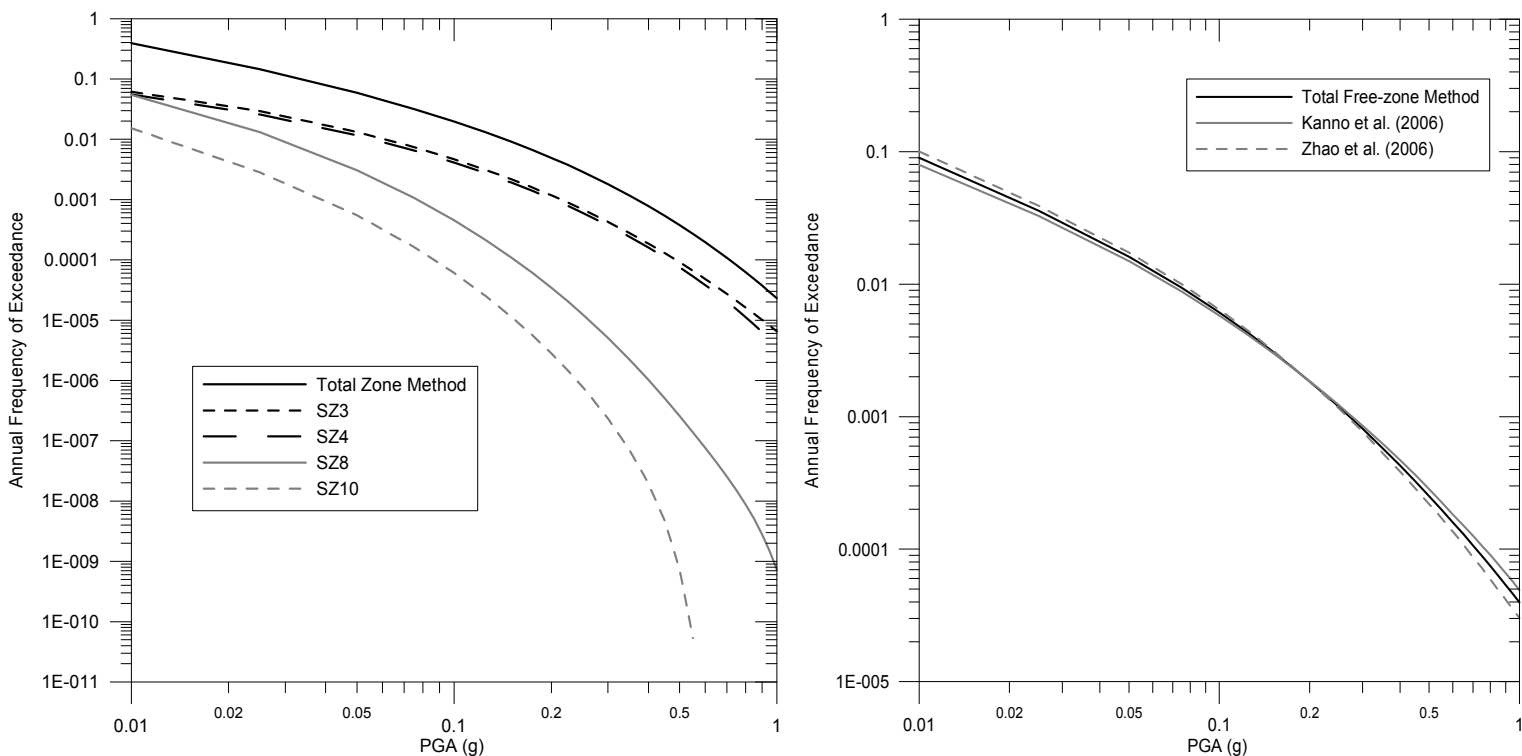

Fig. 14 Hazard curves of Kingston metropolitan area in terms of peak ground acceleration.

response spectrum recommended by the North American Building Codes [12, 52] for rock site conditions, "site class B", is provided in Fig. 15. The United States spectral shape has been scaled to the spectral acceleration at $0.2 \mathrm{~s}$ and $1.0 \mathrm{~s}$ computed in this study for KMA. It is of practical interest to see that the spectrum calculated in this study is in good agreement with the Ref. [12] elastic response spectrum. 


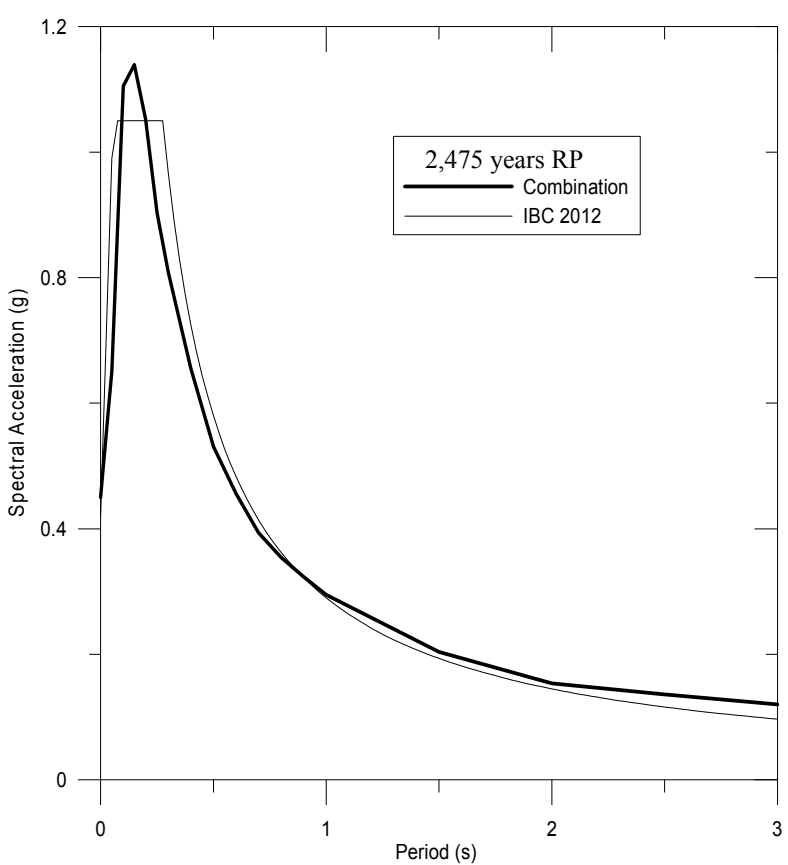

(a)

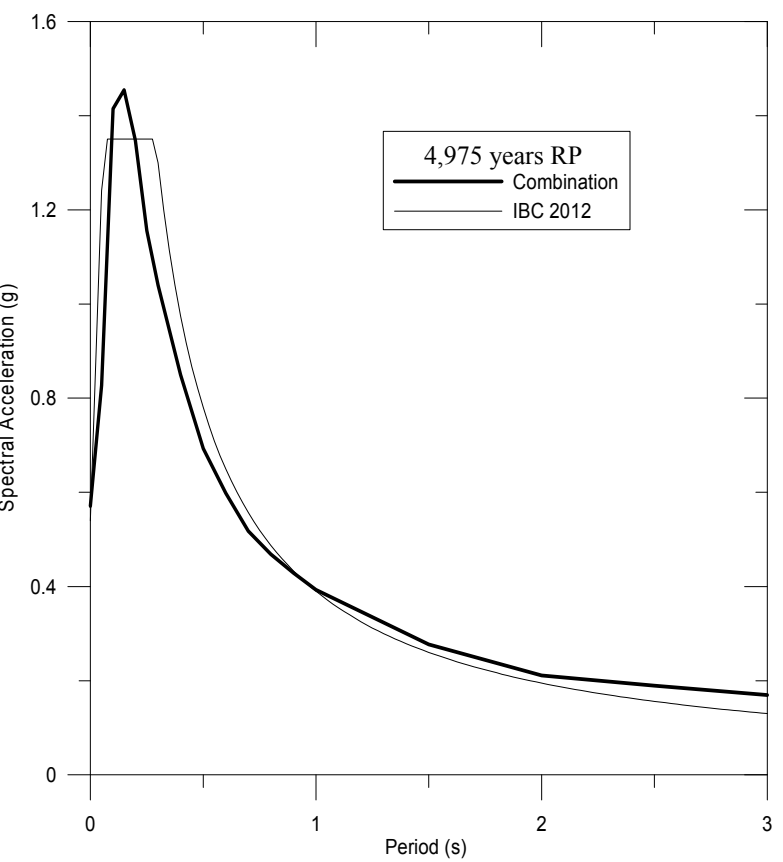

(b)

Fig. 15 Comparison between the mean of the UHS for (a) 2,475-yr and (b) 4,975-yr return period for Kingston metropolitan area (thick line, coordinate $18^{\circ} \mathrm{N}, 7^{\circ} .8^{\circ} \mathrm{W}$ ) and the elastic response spectrum (thin line) of the International Building Code [12].

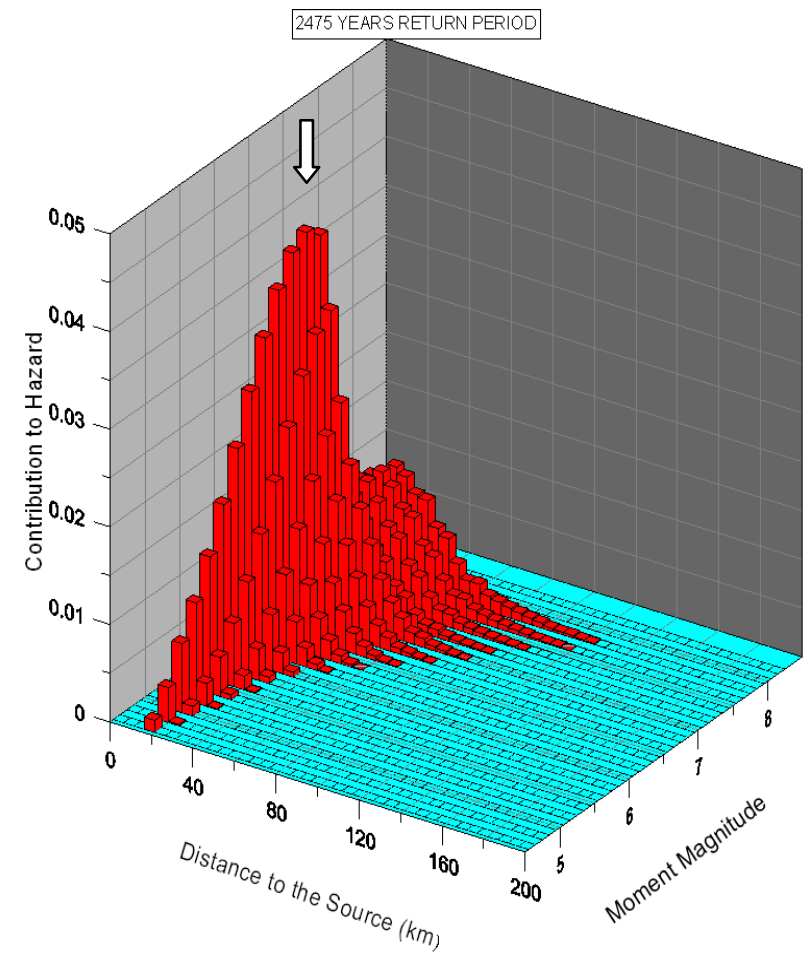

(a)

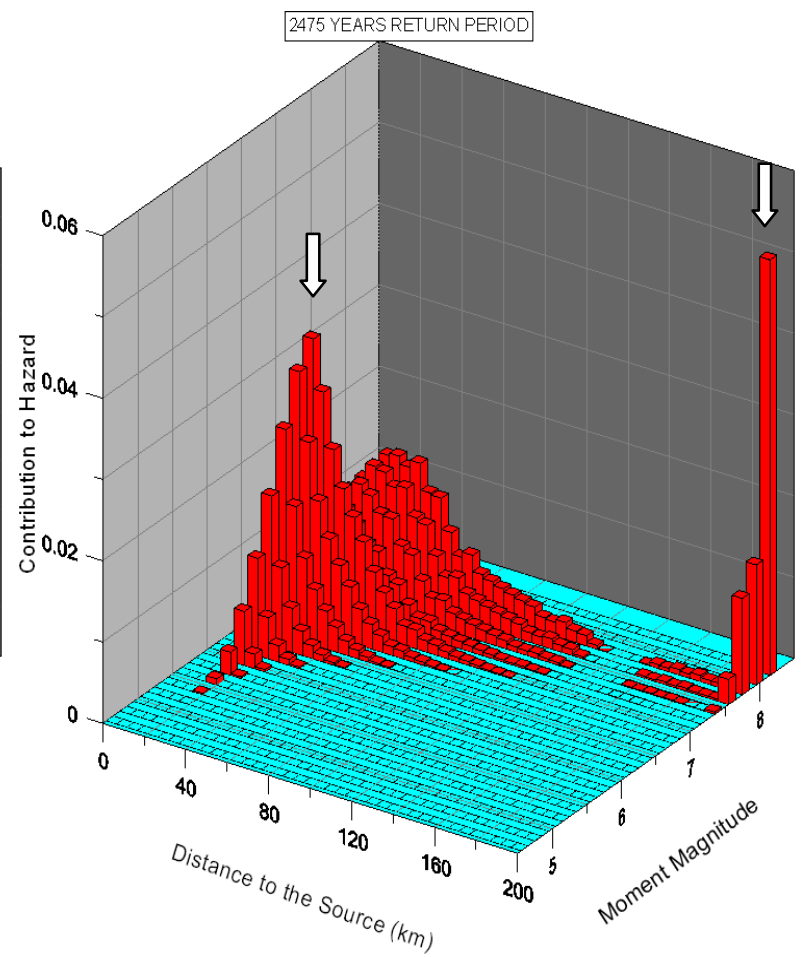

(b)

Fig. 16 Example of disaggregation charts for (a) magnitude-distance pairs for PGA and (b) SA at $T=1.0$ s for 2,475 years return period in Kingston metropolitan area, the magnitude-distance pair that dominates the hazard is indicated by the white arrows. 


\subsection{Disaggregation of Seismic Hazard}

For its integral nature, PSHA combines the contribution to the hazard from all the considered sources to provide the estimate at the site of a ground motion parameter of interest with a certain probability of exceedance during a specified period of time. Therefore, the physical image of an earthquake in terms of magnitude and source-to-site distance is lost in the PSHA analysis. However, through disaggregation it is possible to identify one or more earthquakes giving the largest contribution to the hazard [54].

In fact, the disaggregation process separates the contributions to the mean annual rate of exceedence of a specific ground-motion value at a site due to scenarios of given magnitude $(M)$, source to site distance $(R)$, and, often, the ground-motion error term $\varepsilon$ (number of standard deviations by which the logarithmic ground motion generated by a given $M-R$ pair deviates from the median value estimated by a prediction equation). Thus, this process reveals which earthquake scenarios defined by specific values of $M, R$, and possibly $\varepsilon$ dominate the hazard at the site.

Disaggregation in terms of $M-R$ pair has been computed for:

(1) one site located in Kingston metropolitan area $\left(18^{\circ} \mathrm{N}, 76.8^{\circ} \mathrm{W}\right)$;

(2) three structural periods $(0 \mathrm{~s} / \mathrm{PGA}, 0.2 \mathrm{~s}$ and $1.0 \mathrm{~s})$;

(3) one return period (2,475 years).

The results of the disaggregation analysis are presented in Fig. 16 suggesting that the magnitude-distance pair that contributes most to the hazard corresponds to events with M 7.8 and M 7.0 presumably in the Enriquillo Plantain Garden Fault and the Jamaican Faults at a distance of $28 \mathrm{~km}$ and 18 for short (PGA) and long period (1.0 s) structures respectively corresponding to 2,475 years return period. However, for long period structures $(1.0 \mathrm{~s})$, a substantial contribution is found for a M 8.2 at a distance of $198 \mathrm{~km}$ in the Oriente Fault Zone.

\section{Conclusions}

The scope of the research presented here was to carry out seismic hazard macrozonation of Jamaica and surrounding area based on a state of-the-art PSHA study. PSHA has been performed using the classical Cornell-McGuire and zone-free approaches [4, 5, 13]. Hazard maps have been developed for horizontal ground motion on outcropping bedrock conditions, thereby neglecting local site amplification effects at this stage and presenting the level of uncertainty for each return period.

The present study has shown that Jamaica is characterized by medium-high seismic hazard. The horizontal peak ground acceleration expected on stiff ground, with a $10 \%$ probability of exceedence in 50 years, which corresponds to 475 years return period, ranges between $0.24 \mathrm{~g}$ and $0.30 \mathrm{~g}$ at the eastern part of the Island in the Blue Mountain region. A level of 0.18 $\mathrm{g}$ is obtained for the western part of the Island.

The computation of spectral accelerations at periods of $0.2 \mathrm{~s}$ and $1.0 \mathrm{~s}$ and $\mathrm{RP}$ of 2,475 and 4,975 years assures compatibility with the prescriptions of the International Building Codes [12, 52]. The good agreement achieved between the computed hazard spectra and the spectra adopted by IBC (2012) makes this study useful for seismic code purposes and seismic design of structures in Jamaica. Moreover, the results for the disaggregation scheme in Kingston metropolitan area yield information to generate strong ground motion scenarios to compute earthquake loss estimation in the KMA.

A new dense strong motion network for the whole island is a must in order to develop new ground motion prediction equation's that reflects the features of the source, path and site effects of the earthquakes in Jamaica and surrounding areas, neighboring countries as Cuba, Haiti and Dominican Republic might be cooperative in this regard. The incorporation of slip rates in the future hazard computation is a clear line of research for future computations of Hazard in Jamaica, 
this effort must be done in collaboration with Geodesy research for the region.

\section{Acknowledgments}

Earthquake global data have been obtained from the following internet databases: ISC (International Seismological Centre, 2010). International Seismological Centre, Berkshire, England [55]; Centroid Moment Tensor Solutions [56]; NEIC (National Earthquake Information Center) Centennial [57]; ANSS (Advanced National Seismic System) [58] and the NGDC (National Geophysical Data Center) [59].

The computer program EZ-FRISK ${ }^{\circledR}$ 7.62, a software for earthquake ground-motion estimation, developed by Risk Engineering Inc., has been used for the Cornell-McGuire seismic hazard computations.

The authors greatly thank Gordon Woo (RMS, London) to allow us to use his KERFRACT Fortran Program for Seismic Hazard Calculations. Maps have been prepared using ESRI ArcMap 10.1 (Arc View) Geographic Information System and Surfer 8.0. Lloyd Lynch from SRC (UWI) provided a digital copy of the IPGH earthquake catalogue of Tanner and Shepherd [9] and macroseismic information for Jamaica from Tomblin and Robson [15]. The authors thank to Margaret Wiggins-Grandinson to allow using Fig. 3.

This study has been funded by the World Bank as a part of the Risk Atlas Project for the Caribbean under the supervision of the DRRC (Disaster Risk Reduction Centre) at the University of the West Indies, Mona, Jamaica.

\section{References}

[1] J. Pereira, D. Gay, An engineering risk analysis for Trinidad and Jamaica, in: Proceedings of 1st Caribbean Earthquake Engineering Conference, Port-of-Spain, Trinidad, 1978, pp. 71-92.

[2] J.B. Shepherd, W.P. Aspinall, Seismicity and earthquake hazard in Trinidad and Tobago, West Indies, Earthquake Eng. Struct. Dyn. 11 (1983) 229-250.

[3] C.M. McQueen, An evaluation of seismic hazard in the Caribbean and Central America using three probabilistic methods, Ph.D. Thesis, University of Lancaster, 1997, p. 342.

[4] C.A. Cornell, Engineering seismic risk analysis, Bull. Seismol. Soc. Am. 58 (1968) 1583-1606.

[5] R.K. McGuire, FORTRAN Computer Program for Seismic Risk Analysis, Open-File report, U.S. Geological Survey, 1976, pp. 67-76.

[6] E. Gumbel, Statistics of Extremes, Columbia University Press, USA, 1958, p. 375.

[7] K. Makropoulous, P. Burton, Hazan: A fortran program to evaluate seismic-hazard parameters using Gumbel's theory of extreme value statistics, Computers \& Geosciences 12 (1) (1986) 29-46.

[8] D. Veneziano, C.A. Cornell, T. O'Hara, Historic Method of Seismic Hazard Analysis, Electric Power Research Institute, Palo Alto, USA, 1984.

[9] J.G. Tanner, J.B. Shepherd, Seismic Hazard in Latin America and the Caribbean, Project Catalogue and Seismic Hazard Maps, Instituto Panamericano de Geografía y Historia, 1997, p. 143.

[10] K.M. Shedlock, Seismic hazard map of North and Central America and the Caribbean, Ann. Geofis. 42 (1999) 977-997.

[11] J. García, D. Slejko, L. Alvarez, L. Peruzza, A. Rebez, Seismic hazard maps for Cuba and surrounding areas, Bull. Seismol. Soc. Am. 93 (2003) 2563-2590.

[12] Strategic Standardization, IBC (International Building Code), Inc., U.S., 2012.

[13] G. Woo, Kernel estimation methods for seismic hazard area source modelling, Bull. Seismol. Soc. Am. 86 (2) (1996) 353-362.

[14] W. Bakun, C. Flores, U. ten Brink, Significant earthquakes on the Enriquillo fault system, Hispaniola, 1500-2010: Implications for seismic hazard, Bull. Seismol. Soc. Am. 102 (2012) 18-30.

[15] J. Tomblin, G. Robson, A Catalogue of Felt Earthquakes for Jamaica, with References to Other Islands in the Greater Antilles, 1564-1971, Mines and Geology Division, Ministry of Mining and Natural Resources, Jamaica, 1977, p. 243.

[16] M.E. Pasyanos, D.S. Dreger, B. Romanowicz, Toward real-time estimation of regional moment tensors, Bull. Seism. Soc. Amer. 86 (1996) 1255-1269.

[17] T. Hanks, D. Boore, Moment-magnitude relation in theory and practice, J. Geophys. Res. 89 (1984) 6229-6235.

[18] T. Hanks, H. Kanamori, A moment magnitude scale, Journal of Geophysical Research 84 (1979) 2348-2350.

[19] P. Mann, F. Taylor, R. Edwards, T. Ku, Actively evolving microplate formation by oblique collision and sideways motion along strike slip faults: An example from the northeastern Caribbean plate margin, Tectonophysics 246 (1995) 1-69. 
[20] D. Manaker, E. Calais, A. Freed, S. Ali, P. Przybylski, G. Mattioli, et al., Interseismic Plate coupling and strain partitioning in the northeastern Caribbean, Geophys. J. Int. 174 (2008) 889-903.

[21] A. Frankel, S. Harmsen, C. Mueller, E. Calais, J. Haase, Documentation for Initial Seismic Hazard Maps for Haiti, Open-File report 2010-1067, U.S. Geological Survey, 2010.

[22] M. Wiggins-Grandinson, Preliminary results from the new jamaican seismograph network, Seismological Research Letters 72 (5) (2001) 525-537.

[23] A. Frankel, S. Harmsen, C. Mueller, E. Calais, J. Haase, Seismic hazard maps for Haiti, Earthquake Spectra 27 (S1) (2011) S23-S41.

[24] M. Wiggins-Grandison, K. Atakan, Sesimotectonics of Jamaica, Geophys. J. Int. 160 (2005) 573-580.

[25] K. Burke, J. Grippi, M. Sengor, Neogene structures in Jamaica and the tectonic style of the northern Caribbean plate boundary zone, Journal of Geology 88 (1980) 375-386.

[26] C. DeMets, M. Wiggins-Grandinson, Deformation of Jamaica and motion of the Gonave microplate from GPS and seismic data, Geophys. J. Int. 168 (2007) 362-378.

[27] B. Benford, C. DeMets, B. Tikoff, P. Williams, L. Brown, M. Wiggins-Grandinson, Seismic hazard along the southern boundary of the Gonave microplate: Block modeling of GPS velocities from Jamaica and nearby islands, northern Caribbean, Geophys. J. Int., 190 (1) (2012) 59-740.

[28] J.W. Ladd, T.L. Holcombe, G.K. Westbrook, N.T. Edgar, Caribbean marine geology, active margins of the plate boundary, in: G. Dengo, J.E. Case (Eds.), The Geology of North America, The Caribbean Region, A Decade of North American Geology, 1990.

[29] S. Leroy, A. Mauffret, P. Patriat, B. Mercier, An alternative interpretation of the Cayman Trough evolution from a reidentification of magnetic anomalies, Geophys. J. Int. 141 (3) (2000) 539-557.

[30] C. DeMets, P. Jansma, G. Mattioli, T. Dixon, G. Farina, R. Bilman, et al., GPS geodetic constraints on Caribbean-North America plate motion, Geophys. Res. Lett. 27 (2000) 437-440.

[31] G. Drapper, T. Jackson, S. Donovan, Geological Provinces of the Caribbean Region, Caribbean Geology: An Introduction, U.W.I. Publisher's Association, Kingston Jamaica, 1994, pp. 3-12.

[32] T. Donelly, The Caribbean Sea Floor, U.W.I. Publisher's Association, Kingston Jamaica, 1994, pp. 41-64.

[33] L. Orbera, B. Gonzalez, T. Chuy, J. Oro, Seismic Investigation in the Region of the Nuclear Research Center Site, Reseearch report sponsored by CENAIS and SEAN, 1990, pp. 1-344. (in Spanish)
[34] G. Drapper, J. Barros, Cuba, Caribbean Geology: An Introduction, U.W.I. Publisher's Association, Kingston Jamaica, 1994, pp. 65-86.

[35] T. Pindell, Evolution of the Gulf of Mexico and the Caribbean, Caribbean Geology: An Introduction, U.W.I. Publisher's Association, Kingston Jamaica, 1994, pp. $13-40$.

[36] J.K. Gardner, L. Knopoff, Is the sequence of earthquakes in southern California, with aftershocks removed, Poissonian?, Bull. Seismol. Soc. Am. 64 (1974) $1363-1367$

[37] J. Woessner, S. Wiemer, Assessing the quality of earthquake catalogues: Estimating the magnitude of completeness and its uncertainty, Bull. Seismol. Soc. Am. 95 (2005) 684-698.

[38] J. Stepp, Analysis of completeness of the earthquake catalogue sample in the Puget Sound Area in Seismic Zoning, S.T. Harding, (Ed.), NOAA Tech. report ERL 267-ESL30, Boulder, Colorado, 1973.

[39] S. Tinti, F. Mulargia, Completeness analysis of a seismic catalogue, Ann. Geofis 3 (1985) 407-414.

[40] R. McGuire, W. Arabasz, An introduction to probabilisitic seismic hazard analysis, Geotechnical and Environmental Geophysics 1 (1990) 333-353.

[41] K. Sadigh, C.Y. Chang, J.A. Egan, F. Makdisi, R.R. Youngs, Attenuation relationships for shallow crustal earthquakes based on California strong motion data, Seismological Research Letters 68 (1) (1997) 180-189.

[42] T. Kanno, A. Narita, N. Morikawa, H. Fujiwara, Y. Fukushima, A new attenuation relation for strong motion in Japan based on recorded data, Bull. Seismol. Soc. Am. 96 (3) (2006) 879-897.

[43] J.X. Zhao, J. Zhang, A. Asano, Y. Ohno, T. Oouchi, T. Takahashi, et al., Attenuation relations of strong ground motion in Japan using site classification based on predominant period, Bull. Seismol. Soc. Am. 96 (3) (2006) 898-913.

[44] N. Abrahamson, W. Silva, Summary of the Abrahamson \& Silva NGA ground-motion relations, Earthquake Spectra 24 (1) (2008) 67-97.

[45] B. Chiou, R. Youngs, An NGA model for the average horizontal component of peak ground motion and response spectra, Earthquake Spectra 24 (1) (2008) 173-215.

[46] R.R. Youngs, S.J. Chiou, W.J. Silva, J.R. Humphrey, Strong ground motion attenuation relationships for subduction zone earthquakes, Seismological Research Letters 68 (1) (1997) 58-73.

[47] G.M. Atkinson, D.M. Boore, Empirical ground-motion relations for subduction-zone earthquakes and their application to Cascadia and other regions, Bull. Seismol. Soc. Am. 93 (4) (2003) 1703-1729.

[48] P.S. Lin, C.T. Lee, Ground-motion attenuation 
relationships for subduction-zone earthquakes in northeastern Taiwan, Bull. Seismol. Soc. Am. 98 (1) (2008) 220-240.

[49] F. Scherbaum, F. Cotton, P. Smit, On the use of response spectral-reference data for the selection and ranking of ground-motion models for seismic-hazard analysis in regions of moderate seismicity: The case of rock motion, Bull. Seismol. Soc. Am. 94 (6) (2004) 2164-2185.

[50] F. Bozzoni, M. Corigliano, C. Lai, W. Salazar, L. Scandella, E. Zuccolo, et al., Probabilistic seismic hazard assessment at the eastern Caribbean islands, Bull. Seismol. Soc. Am. 101 (5) (2011) 2499-2521.

[51] J. Bommer, C. McQueen, W. Salazar, S. Scott, G. Woo, A case of study of the spatial distribution of seismic hazard (El Salvador), Natural Hazards 18 (1998) 145-166.

[52] Minimum Design Loads for Buildings and Other Structures, American Society of Civil Engineers, ASCE 7-10, 2010, p. 658.
[53] C. Cramer, R. Wheeler, C. Mueller, Uncertainty analysis for seismic hazard in the southern Illinois basin, Seismological Research Letters 73 (2002) 792-805.

[54] M. Chapman, A probabilistic approach to ground-motion selection for engineering design, Bull. Seismol. Soc. Am. 85 (3) (1995) 937-942.

[55] International Seismological Centre Web Site, http://www.isc.ac.uk/ (accessed Sep.15, 2010).

[56] Centroid Moment Tensor Solutions Web Site, http://www.globalcmt.org/CMTsearch.html (accessed Jan. 1, 2013).

[57] National Earthquake Information Center (NEIC) Centennial Web Site, http://earthquake.usgs.gov/research /data/centennial.php (accessed Sep. 15, 2010).

[58] ANSS (National Seismic System) Web Site, http://www.ncedc.org/anss/ (accessed Sep.15, 2010).

[59] NGDC (National Geophysical Data Center) Web Site, http://www.ngdc.noaa.gov/ (accessed Sep. 15, 2010). 